\title{
Tetraphenylborate Solids Stability Tests
}

by

D. D. Walker

Westinghouse Savannah River Company

Savannah River Site

Aiken, South Carolina 29808

T. B. Edwards

\section{MASTEFS}

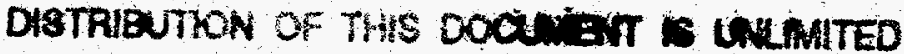

\section{DOE Contract No. DE-AC09-96SR18500}

This paper was prepared in connection with work done under the above contract number with the U.S. Department of Energy. By acceptance of this paper, the publisher and/or recipient acknowledges the U.S. Government's right to retain a nonexclusive, royalty-free license in and to any copyright covering this paper, along with the right to reproduce and to authorize others to reproduce all or part of the copyrighted paper. 


\section{DISCLAIMER}

This report was prepared as an account of work sponsored by an agency of the United States Government. Neither the United States Government nor any agency thereof, nor any of their employees, makes any warranty, express or implied, or assumes any legal liability or responsibility for the accuracy, completeness, or usefulness of any information, apparatus, product, or process disclosed, or represents that its use would not infringe privately owned rights. Reference herein to any specific commercial product, process, or service by trade name, trademark, manufacturer, or otherwise does not necessarily constitute or imply its endorsement, recommendation, or favoring by the United States Government or any agency thereof. The views and opinions of authors expressed herein do not necessarily state or reflect those of the United States Government or any agency thereof.

This report has been reproduced directly from the best available copy.

Available to DOE and DOE contractors from the Office of Scientific and Technical Information, P. O. Box 62, Oak Ridge, TN 37831; prices available from (423) 576-8401.

Available to the public from the National Technical Information Service, U. S. Department of Commerce, 5285 Port Royal Road, Springfield, VA 22161. 


\section{DISCLAIMER}

Portions of this document may be illegible in electronic image products. Images are produced from the best available original document. 
WSRC-TR-97-0285, Rev. 0

\section{TETRAPHENYLBORATE SOLIDS STABILITY TESTS (U)}

D. D. Walker and T.B. Edwards

Publication Date: December 19, 1997

Westingho use Sa vannah River Company

Savannah River Technology Center

Aiken, SC 29808

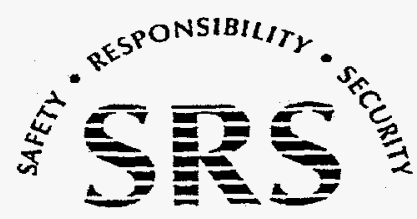




\section{Authors}

Dairel Di. Walker

$12 / 19 / 97$

D. D. Walker, Waste Processing Technology Date

Thmes B Sduando

T. B. Edwards, Statistical Consulting
$12-19-97$

Date

\section{Design Check}

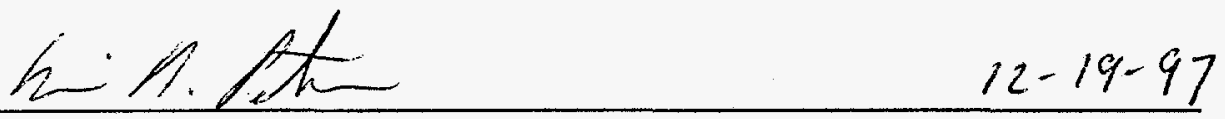

R. A. Peterson, Waste Processing Technology Date (per Manual E7, Procedure 2.40)

\section{Approvals}

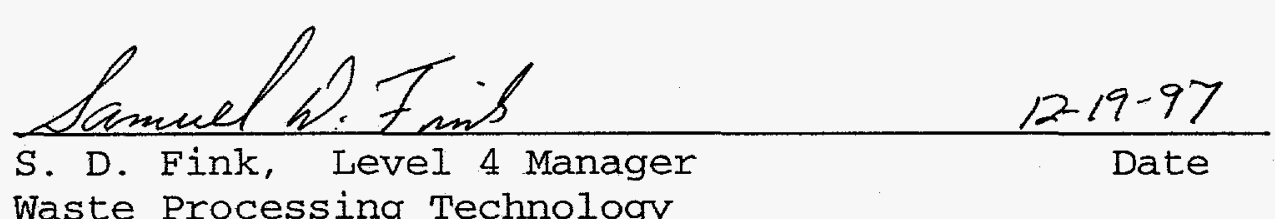
Waste Processing Technology

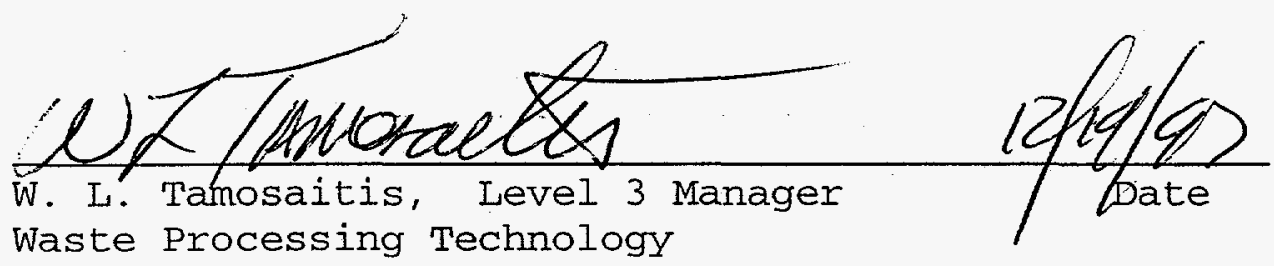
waste Processing Technology
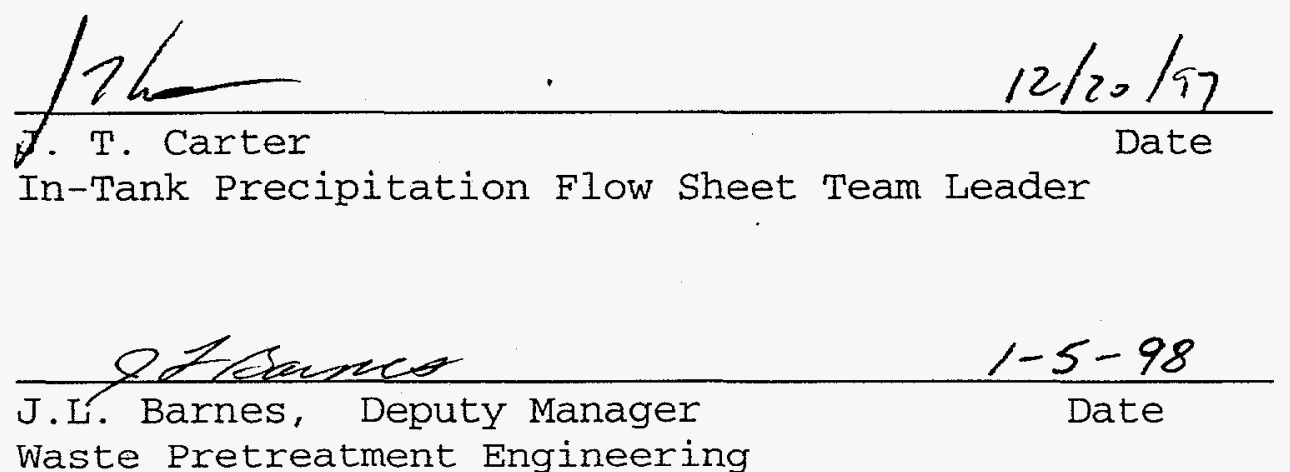
CONTENTS

SUMMARY............................... 5

INTRODUCTION ........................... 6

DIscussIoN.............................

Selection of Variables and Fixed Parameters. 7

statistical Test Design................ 12

Tests of the Effect of pH Adjustment Method

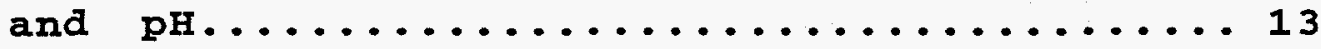

Effect of sludge/Catalyst Concentration.... 14

Test Results........................ 14

Modeling Results..................... 22

statistical Analysis................ 33

Effects of other variables.............. 24

RECOMMENDATIONS FOR FURTHER ACTIONS......... 26

REFERENCES ......................... 27

APPENDIX A: Experimental Details........... 30

APPENDIX B: Statistical Analysis............ 40 


\section{LIST OF FIGURES}

1 Changes in Soluble Potassium Concentration..................... 15

2 Effect of sludge and Noble Metals Concentration on TPB Decomposition Rate. 25

B-1 Paired Comparison of $\mathrm{k}^{+}$Rates.......... 42

\section{IIST OF TABLES}

I

$I I$

III

Summary of Fixed Conditions............ 8

IV

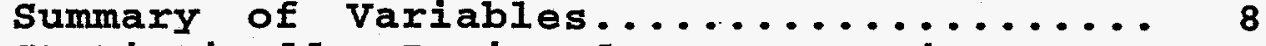

Summary of Test Conditions and Potassium

13

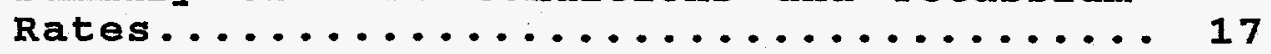

$\mathbf{V}$

Effect of pH Adjustment Method............. 19

VI

Comparison of Yields of Soluble Potassium

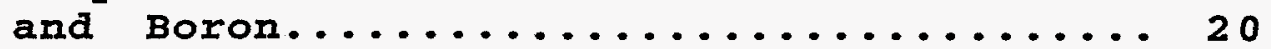

VII

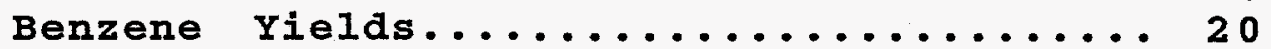

VIII Values of Parameters Used in Modeling Calculations...................... 23

Ix Effect of sludge Concentration......... 25

A-1 simulant slurry compositions............ 30

A-2 Slurry Irradiation and pH Adjustment..... 31

A-3 Catalyst Components in simulant slurries. 32

A-4 Analytical Results for solids Tests..... 35

A-5 Comparison of Initial and Repeat Analyses of Samples Showing High $\mathrm{K}^{+}$and NaTPB.... 39

B-1 Experimental Design and Results..........40

B-2 Results from Fitting the statistical Model 41

$\mathrm{B}-3$

Results from Fitting Additional

statistical Models.................42 
WSRC-TR-97-0285 Rev.0

Page 5 of 44

\section{TETRAPHENYLBORATE SOLIDS STABILITY TESTS}

BY D. D. WALKER and T. B. EDWARDS

\section{SUMMARY}

Tetraphenylborate solids provide a potentially large source of benzene in the slurries produced in the In-Tank

Precipitation (ITP) process. The stability of the solids is an important consideration in the safety analysis of the process and we desire an understanding of the factors that influence the rate of conversion of the solids to benzene. This report discusses a statistically designed set of tests that measured the effects of four variables: sodium ion concentration, $\mathrm{pH}$ (or hydroxide ion concentration). irradiation dose prior to test, and continuous radiation during test. The appearance of soluble potassium indicates the loss of potassium tetraphenylborate solids (KTPB). The following points summarize the test results.

- The rates of increase in soluble potassium vary from 1 to $178 \mathrm{mg} / \mathrm{L} /$ day at $45^{\circ} \mathrm{C}$. This range exceeds that expected from previous tests at 40 and $50{ }^{\circ} \mathrm{C}$ and is similar to the range observed when the temperature varied from 40 to $70^{\circ} \mathrm{C}$.

- The highest rates (>35 $\mathrm{mg} / \mathrm{L} /$ day) occur at the worst case combination of variables and reflect an artifact of the statistical experimental matrix. These conditions will not occur in ITP operations.

- The higher rates largely result from the five-fold higher sludge and catalyst concentrations in these tests. The rate of increase in potassium is directly proportional to the amount of sludge and noble metal catalyst present.

- The two-mechanism model that correlated previous tests predicts lower $\mathrm{K}^{+}$rates than were measured in 10 of the 14 tests. The model worked only for those tests that reacted slowly. This result suggests that the model is incomplete (i.e., an additional mechanism exists).

- Statistical analysis of the results determined low pH and high sodium ion concentration are significant factors in promoting the decomposition of KTPB.

- Continuous radiation is a significant factor in retarding the decomposition rate.

- The statistical model provided poor reproduction of the measured values. The $\mathrm{R}^{2}$ measure of the fit (i.e., the 
WSRC-TR-97-0285 Rev.0

Page 6 of 44

fraction of the variability of the measurements explained by the modell) was 0.58 . The lack of fit suggests an additional variable affected the reaction rate.

- The experimental method used to adjust the pH (addition of nitric acid) did not affect the rates of decomposition.

Recommendations are made for additional work to improve definition of the decomposition rate within the ITP operating window and improve our understanding of the reaction

mechanism. The additional experimental work in progress will determine reaction rates at the edges of the ITP waste composition operating window and identify basic features of the reaction mechanism. With the additional rate measurements and understanding, a better predictive model can be constructed.

\section{INTRODUCTION}

Previous measurements of the rate of increase in soluble potassium and cesium from the decomposition of KTPB slurries suggested temperature as a possible major controlling factor. ${ }^{1}$ The slurry compositions used in those radioactive and simulant tests had compositions similar to the waste in the first ITP operations. ${ }^{2}$ Based on that earlier work, researchers developed a two-mechanism model for changes in potassium concentration. The two mechanisms included radiolytic degradation of solid and catalytic decomposition of soluble tetraphenylborate ion (TPB'). Results from the model were compared to the observations from facility operations and from laboratory tests with radioactive waste and simulants. The model adequately predicted the waste tank observations and the low temperature laboratory work. In this most recent study, additional simulant tests over a range of waste compositions and radiolysis rates were undertaken at $45^{\circ} \mathrm{C}$ to expand the data base for the model and to search for additional factors that affect the rate of. decomposition. The design and results of these tests are described in this report.

The results of these tests are summarized in reaction rates for the appearance of soluble potassium in solution. One use of these results is to estimate the rate of production of benzene. The relationship between the two rates can be easily calculated from the assumption that complete decomposition of one mole of potassium tetraphenylborate (KTPB) produces one mole of potassium ions and four moles of benzene. This calculation provides a conservative estimate of benzene production since some phenyl groups convert to pehnol and other products. Also, the subsequent reactions involve an additional delay. To convert a potassium rate ( $\mathrm{mg} \mathrm{K}^{+} / \mathrm{L} /$ day) to a benzene rate (mg benzene/L/hour), simply divide by 3 . 
( $1 \underline{\mathrm{mg} \mathrm{K}^{+}}$) ( 1 mmole $\mathrm{K}^{+}$) ( 4 mmoles benzene) ( $78.12 \mathrm{mg}$ benzene) L-day $39.1 \mathrm{mg} \mathrm{Kt} 1$ mmole $\mathrm{Kt} \quad 1$ mmole benzene

$$
\frac{1 \text { day }}{24 \text { hours }}=0.333 \frac{\mathrm{mg} \text { benzene }}{\mathrm{L} \text {-hour }}
$$

This work fulfills a request from A. W. Wiggins, "TPB Solids Stability, "Technical Task Request \#HLE-TTR-97015, Rev.0, November 14, 1996. The work was performed in accordance with the following plan: M. J. Barnes, R. A. Peterson, and D. D. Walker, "Technical Task Plan for Solids Stability Studies of Tetraphenylborate Slurries (U)," WSRC-RP-96-602, Rev.2, October 24, 1997.

\section{DISCUSSION}

The initial test matrix included 10 experiments statistically designed to explore the effects of salt concentration, hydroxide ion concentration, radiation dose rate, and total irradiation dose. The matrix also included four exploratory tests on the effects of uranium, solids concentration, oxygen, and very large radiation dose. Table I lists the fixed parameters; Table II lists the variables and their ranges. Table III lists the test matrix. Subsequently, additional tests explored the effect of the $\mathrm{pH}$ adjustment step used in the statistically designed experiments, the effect of the sludge and noble metal concentration, and the effect of $\mathrm{pH}$ between $\mathrm{pH} 10$ and $\mathrm{pH} 12$. Table III also lists these additional tests (Runs 15-29).

\section{Selection of Variables and Fixed Parameters for Statistically Designed Tests}

The following paragraphs examine the process conditions and waste components in Tables I and II that could affect the rate of appearance of soluble $\mathrm{K}^{+}$. The text discusses the potential effect of each, and indicates whether each was treated as a single valued parameter or 2-value variable_in the statistically designed test.

\section{Temperature}

Increasing the temperature accelerates the reaction. This effect has been experimentally established in numerous tests. ${ }^{1}$ Ail experiments reported below occurred at $45{ }^{\circ} \mathrm{C}$, a temperature that exceeds the highest expected in future Tank $48 \mathrm{H}$ and Tank $49 \mathrm{H}$ operations.

\section{sludge}

Several experiments suggest the presence of sludge increases the rate of decomposition of tetraphenylborate ion. ${ }^{1,2,3}$. Other evidence suggests the decomposition occurs as a homogeneous reaction between a soluble sludge component and soluble TPB'. 
TABLE I. Summary of Fixed Conditions for statistically Designed Test

$\begin{array}{ll}\text { KTPB } & 5 \mathrm{wt} \% \\ \text { Initial [TPB }] & 0-100 \mathrm{mg} / \mathrm{L} \\ \text { Sludge* } & 1 \mathrm{wt} \% \\ \text { Organics } & 500 \mathrm{mg} / \mathrm{L} 3 \mathrm{~PB} \\ & 250 \mathrm{mg} / \mathrm{L} 2 \mathrm{~PB}, 1 \mathrm{~PB}, \text { phenol } \\ & 750 \mathrm{mg} / \mathrm{L} \text { benzene } \\ & 150 \mathrm{mg} / \mathrm{L} \text { diphenylmercury } \\ \text { Temperature } & 45 \mathrm{C}^{\circ} \\ \text { Atmosphere } & \text { sealed under air } \\ \text { Mixing } & \text { no mixing } \\ \text { Vessels } & \text { glass }\end{array}$

* See Table A-3, Appendix A.

\section{TABLE II. Summary of Variables for statistically Designed Test}

Variable

$\left[\mathrm{Na}^{+}\right]$(molar)

$\left[\mathrm{OH}^{-}\right]$

Dose rate $(\mathrm{rad} / \mathrm{h})$

Pre-test dose (Mrad)

\begin{tabular}{lll}
\multicolumn{3}{c}{ Value } \\
Low & $\frac{\text { Midpoint }}{2.75}$ & $\frac{\text { High }}{5.0}$ \\
0.5 & $\mathrm{pH}=12$ & 3.0 molar \\
$\mathrm{pH}=10$ & $1 \mathrm{E} 4$ & $2 \mathrm{E} 4$ \\
0 & 2.5 & 5 \\
0 & & 5
\end{tabular}

Nevertheless, the data to date do not exclude existence of a heterogeneous reaction (i.e., solid catalyst and soluble tetraphenylborate). Depending on the mechanism (i.e., heterogeneous or homogeneous), addition of sludge should either show no affect or increase the rate of reaction. Therefore, the tests included sludge at nominally 1 wt $\%$ in the slurry $(1.2 \mathrm{~g} / \mathrm{L})$, the highest level expected in the process." This sludge concentration is approximately fivefold higher than used in previous testing. Noble metal concentrations (i.e., $\mathrm{Ru}, \mathrm{Rh}$, and $\mathrm{Pd}$ ) were increased proportionally with the sludge.

For a homogeneous reaction, the sludge composition would have no effect if it contained all of the catalytically active components and enough of each to saturate the solution. If a heterogeneous reaction occurs, the composition of the sludge could have an effect on the rate. Ideally, the simulated sludge should contain maximum levels of the active components at the expense of the inactive components.

These tests used a catalyst system described previously. ${ }^{2}$ Noble metals (i.e., Ru, Rh, and Pd) and copper were added as both insoluble and soluble forms. Mercury was added as mercuric nitrate (forming $\mathrm{HgO}$ in the alkaline slurry) and as 
diphenylmercury. Diphenylmercury accounted for $97 \%$ of the total mercury. Mercury concentrations were not increased in proportion to the amount of sludge. Since researchers suspected no active role for uranium in the reaction system, and because of experimental difficulties in handling radioactive samples, uranium was included in only one experiment. The uranium concentration was $344 \mathrm{mg} / \mathrm{L}$, double the maximum amount expected in 1 wt $\%$ sludge with highest uranium content. ${ }^{5}$

\section{Weight Percentage KTPB solids}

Potassium tetraphenylborate provides the source of reactant (either TPB or KTPB solids) and therefore increasing its concentration should either increase the reaction rate or have no effect. The presence of KTPB solids has been demonstrated experimentally to increase the rate of decomposition of $\mathrm{TPB}^{-}$. In unstirred systems, Barnes ${ }^{6}$ measured higher rates of reaction for $\mathrm{TPB}^{-}$with solids present, although the rate does not increase with increasing KTPB content in the range $1-8$ wt $\%$. Tests with Tank $48 \mathrm{H}$ slurries ${ }^{1}$ that varied KTPB and sludge simultaneously showed increased reaction rates at higher concentrations. However, this result could reflect either the higher KTPB content or the higher sludge content.

For a homogeneous reaction (i.e., soluble catalyst and soluble tetraphenylborate), additional KTPB might have no effect if the lowest concentration tested is sufficient to maintain the solution saturated with $\mathrm{TPB}^{-}$. For a heterogeneous reaction (i.e., solid KTPB and soluble catalyst), increasing the KTPB solids concentration could increase the rate of reaction by providing more surface area. A third possibility, the reaction between solid catalyst and solid KTPB is highly unlikely because the reaction zone (solid-solid contact points) is too limited to support a significant reaction rate. Therefore, to obtain conservatively high reaction rates, the KTPB solids concentration should be included at the highest expected level. Current operating plans include concentrating to 10 wt $\%$. A slightly higher concentration (12 wt $\%$ ) would bound experimental and tank uncertainties.

However, preparing, handling, and sampling unirradiated 12 wt $\frac{\%}{8}$ slurry proves very difficult due to its high viscosity and yield strength. Most previous testing used slurries near 5 wt $\%$. Therefore, to provide better comparison to the current data base and to alleviate experimental problems, 5 wt \% slurry was used. An additional test run was made at 2.5 wt $\%$ KTPB to determine if there is a significant effect from the KTPB solids concentration. 


\section{Oxygen}

The presence of oxygen has been shown to delay or suppress the decomposition of tetraphenylborate. ${ }^{2,7,8}$ Some evidence to the contrary has been observed for decomposition of other components (i.e., presence of oxygen speeds decomposition of $2 \mathrm{~PB}$ and 1PB). The presence of oxygen also tends to produce phenol rather than benzene as the final product. Thus, the conservative approach to these tests (i.e., to maximize benzene generation) suggests that oxygen should be excluded. However, due to experimental difficulties inherent in maintaining samples inerted, the tests were run under air but in sealed vessels. Two exploratory experiments under nitrogen was included to provide insight on the effect of this parameter.

\section{Initia] [TPB]}

Previous testing in the Shielded Cells with Tank 48H slurry samples targeted 100 and $400 \mathrm{mg} / \mathrm{L}$ excess NaTPB as an initial condition. ${ }^{1}$ Actual initial conditions ranged from 33 to $360 \mathrm{mg} / \mathrm{L}$. This initial condition did not affect the eventual rate of increase, although higher values delay the onset of the increases in soluble potassium. The initial [TPB'] was included as a variable because its presence might be required to "condition" the catalyst (i.e., provide a reducing agent to obtain a lower oxidation state). These tests targeted $>10$ but $<100 \mathrm{mg} / \mathrm{L}$ of NaTPB for the initial condition. In several cases, the initial NaTPB was less than detectable $(<10 \mathrm{mg} / \mathrm{L})$.

\section{Mixing}

Mixing normally enhances chemical reactions, but recent test results indicate that continuous mixing in a sealed system does not significantly affect the rate of decomposition of $\mathrm{TPB}^{-}$. Barnes' results indicate a $20 \%$ increase in rate when sludge solids in a salt solution are continuously mixed (compared to unmixed).9 However, if KTPB solids are present, mixing a sludge/slurry does not affect the rate measurably. The slurries were not mixed in these tests.

\section{Benzene, organic intermediates, and diphenylmercury}

Experimental evidence exists that indicates the presence of triphenylborane (3PB), diphenylborinic acid (2PB), and phenylboronic acid (1PB) influence $\mathrm{TPB}^{-}$and $3 \mathrm{~PB}$ decomposition. ${ }^{10}$ These organics appear to consume oxygen, possibly leading to reduction of the catalytic metal ion to the active oxidation state. ${ }^{8}$ This explains an induction effect but implies that the final decomposition rate remains unchanged. Benzene is also implicated in the catalytic system. ${ }^{10}$ It may form a non-aqueous phase that promotes the decomposition, but experimental support is lacking. In any 
rapid reaction in a sealed system, these compounds will accumulate even if not present initially. However, their absence may slow the onset of the reaction. Because of the potential induction effect, benzene and organic intermediates were included at high initial levels. Concentrations of intermediates ( $3 \mathrm{~PB}, 2 \mathrm{~PB}$, and $1 \mathrm{~PB})$ double those used in previous catalyst testing were targeted $(250 \mathrm{mg} / \mathrm{L}$ of $3 \mathrm{~PB}$, $2 \mathrm{~PB}, 1 \mathrm{~PB}$, and phenol). Benzene was held the same as previous testing $(750 \mathrm{mg} / \mathrm{L})$.

Diphenylmercury was added as a fixed component of the slurry at the same level used in catalyst identification testing $(150 \mathrm{mg} / \mathrm{L})$.

\section{Total radiation dose}

The effect of a large adsorbed radiation dose on the rate of appearance of soluble $\mathrm{K}^{+}$is not known. Barnes has shown that a dose of 200 Mrad does not accelerate decomposition of soluble TPB-.11 Comparison of Crawford's tests (no dose) ${ }^{12}$ and other tests (Tk 48H samples, irradiated simulants) ${ }^{1}$ and the agreement of the model with Tank $48 \mathrm{H}$ results ${ }^{1}$ suggest little impact from doses in the range 5 to $200 \mathrm{Mrad}$. Since a direct investigation of the effect of radiation dose on solids stability is not available, pre-irradiation was included as a 2-level variable.

The Tank $48 \mathrm{H}$ solids have received an estimated average dose of 200 Mrad. Rate differences between simulated slurries irradiated to $5 \mathrm{Mrad}$ and Tank $48 \mathrm{H}$ slurries prove minimal. ${ }^{1}$ However, the rheological properties of slurries change significantly with doses of 15 to 30 Mrad. ${ }^{13}$ Thus, preirradiation to doses of 0 and $30 \mathrm{Mrad}$ was used to encompass the rheological changes. In addition, a single exploratory experiment with a slurry irradiated to 200 Mrad was included at the centerpoint composition $\left(2.8 \mathrm{M} \mathrm{Na}^{+}, \mathrm{pH} 12\right)$ and radiation conditions (15 Mrad adsorbed dose, $1.5 \times 10^{4} \mathrm{rad} / \mathrm{h}$ continuous dose) to provide insight on the effect of long storage times.

\section{salt concentration}

The salt (or total sodium ion) concentration can affect the rate in three ways, two of which have been experimentally verified. First, increasing the salt concentration decreases the solubility of tetraphenylborate compounds. ${ }^{14}$ This will decrease the rate of a reaction involving TPB ion but might have no effect on a reaction involving NaTPB or KTPB solids. Second, experimental evidence indicates the rate constant for decomposition of $\mathrm{TPB}^{-}$ion increases with salt concentration, ${ }^{6}$ possibly due to an ionic strength affect. Third, if a salt component is part of the catalytic system, then increasing its concentration could affect the rate of appearance of soluble $\mathrm{K}^{+}$. Work by Barnes has not identified any salt 
components active in the catalytic system in TPB decomposition. "Since the first two effects oppose one another, it is not clear whether the fastest rates will occur at low or high salt concentrations. Total sodium ion concentration was treated as a 2-level variable at 0.1 and 5.5 molar to bound salt concentrations expected in Tank $48 \mathrm{H}$, Tank 49H, and the Late Wash Facility.

\section{$\mathrm{OH}^{-}$Or $\mathrm{pH}$}

Hydroxide ion or $\mathrm{pH}$ is an important factor in stabilizing $\mathrm{TPB}^{-}$ purchased from vendors. Although the metal-catalyzed decomposition mechanism for $\mathrm{TPB}^{-}$ion appears independent of $\mathrm{OH}^{-}$in the range 0.5 to 3 molar, ${ }^{6}$ a general acid catalyzed mechanism is rapid at low $\mathrm{pH} .{ }^{15}$ The current ITP process requirements ${ }^{16}$ include the possibility for storage of washed precipitate in Tank $49 \mathrm{H}$ under conditions where the $\mathrm{pH}$ will drop to approximately 10.3. The irradiated slurry is buffered at $\mathrm{pH} 10$ by a mixture of phenol and carbonate so Late washing will not reduce the $\mathrm{pH}$ significantly. It is possible that the acid catalyzed mechanism may be important at this $\mathrm{pH}$. However, the solubility of $\mathrm{Cu}$ and other metal ions decrease as the $\mathrm{pH}$ drops from 14 to $10 .{ }^{17}$ Thus, the metal-catalyzed reaction could be slower at the lower $\mathrm{pH}$. Since these two effects oppose each other, the hydroxide concentration was tested $\mathrm{pH} 10$ to $\mathrm{pH} 14.5$ (3 M NaOH).

\section{Radiation dose rate}

Radiation affects the appearance of $\mathrm{K}^{+}$in solution due to the degradation of KTPB solids and $\mathrm{TPB}^{-}$ion. ${ }^{1}$ At dose rates expected in ITP operations, decomposition of TPB from radiation is negligible compared to the catalyzed reaction. ${ }^{11}$ However, in the absence of the rapid catalytic reaction, radiation will contribute significantly to the total decomposition rate. Thus, radiation was included as a 2level variable to determine how changes in the dose rateaffect the total decomposition rate.

\section{statistical Test Design}

Several options for statistically designed tests for four variables were considered, including a full factorial with centerpoints (18 runs). A partial factorial design was selected to reduce the time. From statistical considerations, a linear model of the variables can be tested in 8 runs with two centerpoints. This design provides main effects and insight on 2-way interactions. Additional runs outside of the statistical design were included to investigate effects of nitrogen inerting, weight percentage KTPB, uranium, and very large radiation dose. Table III lists the test matrix.

The centerpoint conditions in a linear model are normally taken as the arithmetic average of the high and low values. 
TABLE III. Statistically Designed Test Matrix

\begin{tabular}{|c|c|c|c|c|}
\hline Run & {$\left[\mathrm{Na}^{+}\right]$} & {$\left[\mathrm{OH}^{-}\right]$} & Preirrad. & Dose \\
\hline $1^{*}$ & +1 & +1 & -1 & -1 \\
\hline $2^{*}$ & +1 & +1 & +1 & $+\overrightarrow{1}$ \\
\hline $3 *$ & $+\overline{1}$ & -1 & -1 & +1 \\
\hline $4^{*}$ & +1 & $-\overline{1}$ & +1 & -1 \\
\hline $5 *$ & 0 & 0 & 0 & $\overline{0}$ \\
\hline $6 *$ & 0 & 0 & 0 & 0 \\
\hline 7 (Uranium) & 0 & 0 & 0 & 0 \\
\hline 8 (High pre-dose) & 0 & 0 & 0 & 0 \\
\hline $9 *$ & -1 & +1 & -1 & +1 \\
\hline $10^{*}$ & -1 & +1 & +1 & -1 \\
\hline $11 *$ & -1 & -1 & -1 & -1 \\
\hline $12\left(\mathrm{~N}_{2}\right.$ inerted $)$ & -1 & -1 & -1 & -1 \\
\hline $13 * 2$ & -1 & -1 & +1 & +1 \\
\hline 14 (2.5 wt \% KTPB) & -1 & -1 & +1 & +1 \\
\hline 15 (Run $5 / 6$ repeat at $\mathrm{pH} 10$ ) & 0 & -1 & 0 & 0 \\
\hline 16 (Run 5/6 repeat at pH10) & 0 & -1 & 0 & 0 \\
\hline $17\left(\mathrm{~N}_{2}\right.$ inerted $)$ & 0 & -1 & 0 & -1 \\
\hline 18 (2.5 wt $\% \mathrm{KTPB})$ & 0 & -1 & 0 & +1 \\
\hline
\end{tabular}

* Indicates tests that are part of the statistical design. $+1,0$, and -1 indicate high, centerpoint, and low values for the variables. See Table II for numerical values. Other tests are not part of the statistical design.

In this test, the center point values for three of the variables (salt concentration, dose rate, and total dose) were the arithmetic averages. However, the fourth variable (pH) very likely has a nonlinear response, so the centerpoint value was $\mathrm{pH}=12$ rather than $\left[\mathrm{OH}^{-}\right]=1.5 \mathrm{M}$.

The experiment at high $\left[\mathrm{OH}^{-}\right]$and low sodium is not physically accessible. In this case, the experimental parameters were selected as close as possible to the desired point.

Appendix A details the preparation of slurries for the experiments. The tests ran for eight weeks. Samples were taken initially and every seven days. Potassium and $\mathrm{pH}$ measurements were made on all samples. Soluble catalytic metals ( $\mathrm{Cu}, \mathrm{Ag}, \mathrm{Rh}, \mathrm{Pd}$ ) were measured only on initial and final samples. The NaTPB, 3PB, 2PB, 1PB, and phenol concentrations were analyzed on all initial samples and during the first several weeks of the test, but were terminated during the fourth or fifth week because little information was gained from them. 


\section{Tests of the Effect of $\mathrm{pH}$ Adjustment step and $\mathrm{pH}$}

In the statistically designed set of 10 tests, concentrated nitric acid was used to adjust the $\mathrm{pH}$. The amount of acid used was inversely proportional to the desired $\mathrm{pH}$, with several milliliters required for $\mathrm{pH} 10$ slurries and none required for $\mathrm{pH} 14$ slurries. Thus, the correlation between $\mathrm{pH}$ and decomposition rate was confounded with the same correlation between the amount of acid used and decomposition rate. Since an effect due to acid is not representative of the ITP process, four of the statistically designed tests (Table III, Run 3, 4, 11, and 13) were repeated using carbon dioxide to adjust the $\mathrm{pH}$. The nitric acid adjustment method was repeated at the same time.

Four other tests (Run 15-18) at the midpoint sodium concentration were run at $\mathrm{pH} 10$ using the carbon dioxide $\mathrm{pH}$ adjustment method. These tests provide additional data on the effect of the method of adjustment and on the effect of a hydroxide change between $\mathrm{pH} 10$ and $\mathrm{pH} 12$. In particular, Runs 15 and 16 at pH 10 can be compared to Runs 5 and 6 at pH 12. Runs 17 and 18 changed more than one variable, so direct comparisons with other runs are not possible. However, the results were used in the statistical evaluation of the data.

\section{Effect of sludge/Catalyst Concentration}

Three runs at $0.2,1.0$ and 2.0 wt $\%$ sludge and noble metals examined the effect of these components with other variables constant. The slurries for these tests contained $4.5 \mathrm{M} \mathrm{Na}^{+}$. The results of these tests were not included in the statistical analysis of the effects of sodium ion, pH, preirradiation, and dose rate.

\section{Test Results}

\section{Potassium}

The appearance of soluble potassium ion was used as a measure of the loss of tetraphenylborate solids (KTPB and CsTPB). Figure 1 graphs the potassium ion concentrations in the first 14 tests listed in Table IV. Modeling results for each test are also shown in Figure 1 and discussed in the Modeling Results section. Tables $I V$ and $V$ summarize the test conditions and the observed rates of increase in soluble potassium. The following points summarize test observations.

- The rates of increase in soluble potassium vary from 1 to $178 \mathrm{mg} / \mathrm{L} /$ day at $45^{\circ} \mathrm{C}$. This range is similar to the range observed in previous tests over a range of temperatures from 40 to $70{ }^{\circ} \mathrm{C}$ (i.e., 0.1 to $130 \mathrm{mg} / \mathrm{L} /$ day). ${ }^{1}$

- The higher rates largely result from the five-fold higher sludge and catalyst concentrations in these 
FIGURE 1. Changes in Soluble Potassium Concentrations

Note: The vertical scales on these graphs differ. Use care when comparing different experiments.
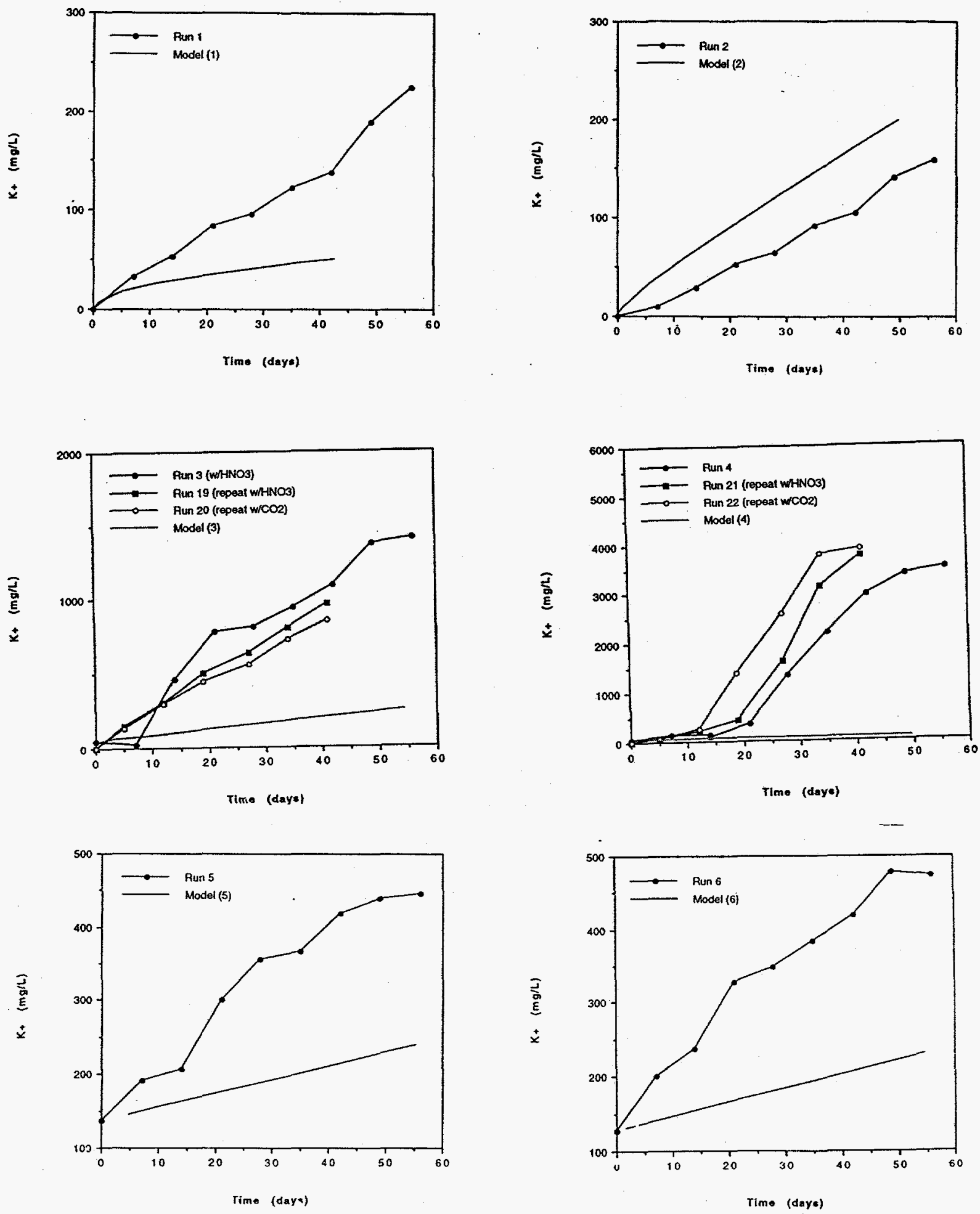
FIGURE 1 (continued). Changes in Soluble Potassium Concentrations

Note: The vertical scales on these graphs differ. Use care when comparing different experiments.
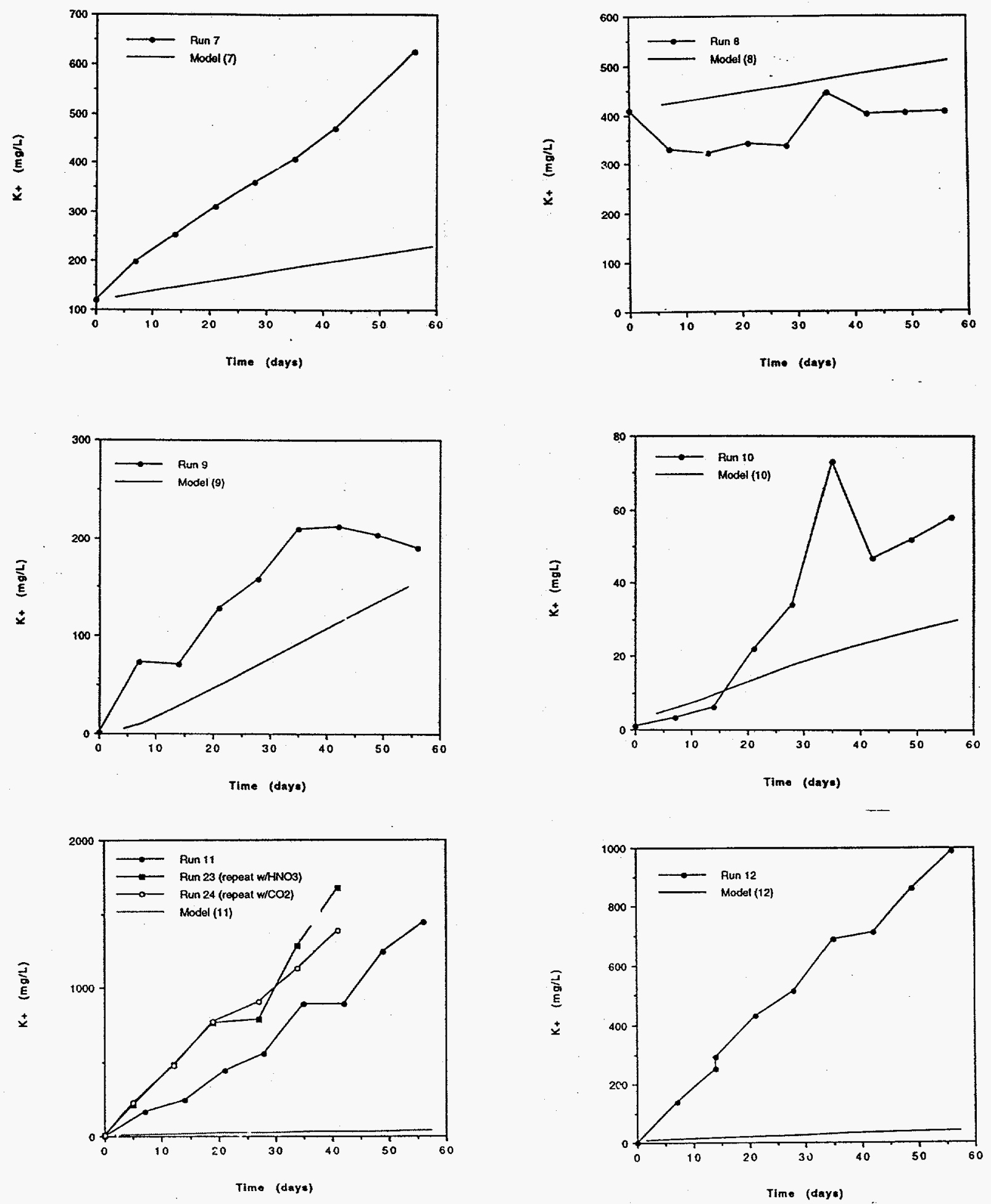
WSRC-TR-97-0285 Rev. 0 Page 17 of 44

FIGURE 1 (continued). Changes in Soluble Potassium Concentrations

Note: The vertical scales on these graphs differ. Use care when comparing different experiments.
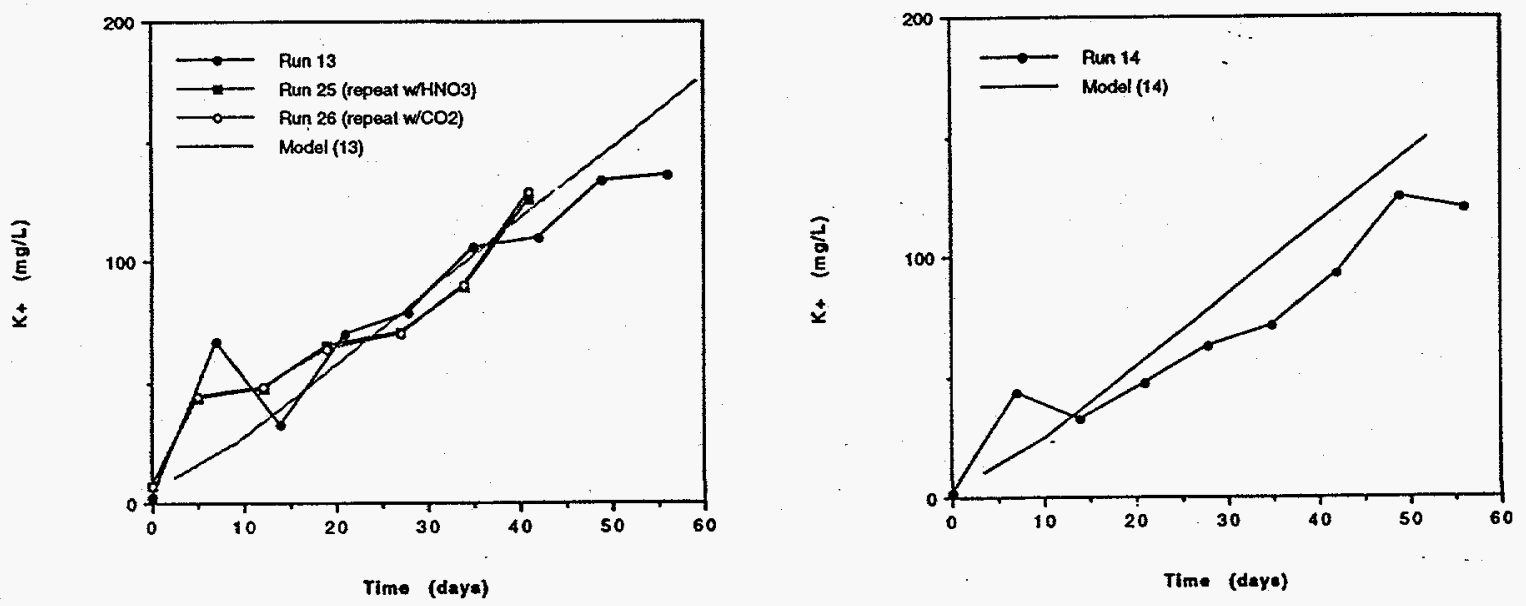

TABLE IV. Summary of Test Conditions and Potassium Rates

\begin{tabular}{|c|c|c|c|c|c|c|}
\hline Run & $\begin{array}{c}{\left[\mathrm{Na}^{+}\right]} \\
(\mathrm{molar})\end{array}$ & $\mathrm{pH}$ & $\begin{array}{c}\text { Pre-test } \\
\text { dose } \\
\text { (Mrad) }\end{array}$ & $\begin{array}{l}\text { Dose } \\
\text { rate } \\
(\mathrm{rad} / \mathrm{h})\end{array}$ & $\begin{array}{r}\mathrm{Sc} \\
\mathrm{K}^{+} \\
\underline{\mathrm{Imc}} \\
\end{array}$ & $\begin{array}{l}\text { luble } \\
\text { Rate } \\
\text { /L/day }\end{array}$ \\
\hline 1 & 5.5 & 14.5 & 0 & 0 & & 3.8 \\
\hline 2 & 5.5 & 14.5 & 30 & $2.8 \times 10^{4}$ & & 2.9 \\
\hline 3 & 5.5 & 10.5 & 0 & $2.8 \times 10^{4}$ & & 26 \\
\hline 4 & 5.5 & 10.7 & 30 & 0 & & 124. \\
\hline 5 & 2.8 & 12.2 & 15 & $1.5 \times 10^{4}$ & & 5.9 \\
\hline 6 & 2.8 & 12.2 & 15 & $1.5 \times 10^{4}$ & & 6.3 \\
\hline 7 & 2.8 & $12: 0$ & 15 & $1.5 \times 10^{4}$ & Uranium & 8.5 \\
\hline 8 & 2.8 & 11.8 & 200 & $1.5 \times 10^{4}$ & Large dose & 1.1 \\
\hline 9 & 0.65 & 13.7 & 0 & $2.8 \times 10^{4}$ & & 5.0 \\
\hline 10 & 0.65 & 13.7 & 30 & 0 & & 1.2 \\
\hline 11 & 0.10 & 10.3 & 0 & 0 & & 26 . \\
\hline 12 & 0.10 & 10.4 & 0. & 0 & $\mathrm{~N}_{2}$ inerted & 17. \\
\hline 13 & 0.10 & 10.2 & 30 & $2.8 \times 10^{4}$ & & 2.2 \\
\hline 14 & 0.10 & 10.1 & 30 & $2.8 \times 10^{4}$ & 2.5 wt 8 KTPB & 2.0 \\
\hline 15 & 2.8 & 10.2 & 15 & $1.5 \times 10^{4}$ & & 15 \\
\hline 16 & 2.8 & 9.9 & 15 & $1.5 \times 10^{4}$ & & 14 \\
\hline 17 & 2.8 & 10.5 & 15 & 0 & $\mathrm{~N}_{2}$ inerted & 19 \\
\hline 18 & 2.8 & 10.2 & 15 & $2.9 \times 10^{4}$ & 2.5 wi $\frac{8}{8} \mathrm{KTPB}$ & 22 \\
\hline
\end{tabular}


tests. The rate of increase in potassium is directly proportional to the amount sludge and noble metal catalyst present.

- The highest rates (>35 mg/L/day) are caused by worst case combination of variables and are an artifact of the statistical experimental matrix. They will not occur in ITP operations.

In 17 of the 18 tests, a significant increase in the soluble potassium occurred. In Run 8 , the change in potassium was not significantly larger than the sampling and analytical errors. In the other tests, the potassium concentration typically increased with time. Although potassium usually increased linearly, clear exceptions are Run 4 and Run 9 and possible exceptions include Runs 3, 5, 6, and 13. In Run 4, the rate increased at 21 days, then slowed near the end of the test. The same response was observed when this run was repeated to test for an effect of the $\mathrm{pH}$ adjustment method. Although other explanations are possible, the slowdown was probably due to the extreme loss of solids; by the end of the test, more than $70 \%$ of the solids decomposed. Decreases in the concentration of soluble palladium does not appear to explain the curvature and slowing of the reaction rate. Although soluble palladium decreased during Run 4 and Run 3, it increased in the other runs that showed or suggested slowing of the rate (see Appendix $A$, Table $A-4$ ).

The rates of increase in soluble potassium varied between 1 and $178 \mathrm{mg} / \mathrm{L} /$ day (Table $\mathrm{IV}$ and $\mathrm{V}$ ). This range is similar to results from previous tests. ${ }^{1}$ However, the large range in previous tests was attributed to differences in temperature. In previous tests, rates larger than $2 \mathrm{mg} / \mathrm{L} /$ day were observed only above $50{ }^{\circ} \mathrm{C}$. The present set of tests indicate that there is a factor that can promote rates greater than 2 $\mathrm{mg} / \mathrm{L} /$ day at $45^{\circ} \mathrm{C}$. The higher concentrations of sludge and catalytically active metals used in the current tests contribute to the higher rates. These tests used five times as much sludge and metals as previous tests. If the potassium rate is directly proportional to the amount of sludge and metals, then rates as high as $10 \mathrm{mg} / \mathrm{L} /$ day are expected. The measurement of rates much higher than $10 \mathrm{mg} / \mathrm{L} /$ day suggests that an additional factor is present.

\section{Effect of $p H$ adjustment method}

The use of nitric acid to adjust pH did not cause the high potassium rates observed at low pH. Table $V$ lists the results of the comparison tests. In the repeat measurements, there was no significant difference between the nitric acid method and the carbon dioxide method. The difference in rates between the initial and repeat runs gives an estimate of $\pm 30 \%$ for the average reproducibility of the experiments. 
TABLE V. Effect of pH Adjustment Method

\begin{tabular}{|c|c|c|c|c|c|c|c|}
\hline Run & {$\left[\mathrm{Na}^{+}\right]$} & {$\left[\mathrm{OH}^{-}\right]$} & $\begin{array}{l}\text { Pre- } \\
\text { irrad. }\end{array}$ & $\begin{array}{l}\text { Dose } \\
\text { rate }\end{array}$ & $\begin{array}{l}\mathrm{pH} \\
\text { Method }\end{array}$ & $\begin{array}{l}\text { Amount } t \\
\text { of } \mathrm{HNO}_{3}\end{array}$ & $\begin{array}{l}\mathrm{K}^{+} \text {rate } \\
(\mathrm{mg} / \mathrm{L} / \text { day })\end{array}$ \\
\hline $\begin{array}{r}3 \\
19 \\
20\end{array}$ & +1 & -1 & -1 & +1 & $\begin{array}{l}\mathrm{HNO}_{3}^{*} \\
\mathrm{HNO}_{3}^{* *} \\
\mathrm{CO}_{2}\end{array}$ & $\begin{array}{l}4.8 \\
5.0 \\
0\end{array}$ & $\begin{array}{l}26 \\
23 \\
20\end{array}$ \\
\hline $\begin{array}{r}4 \\
21 \\
22\end{array}$ & +1 & -1 & +1 & -1 & $\begin{array}{l}\mathrm{HNO}_{3} \text { * } \\
\mathrm{HNO}_{3} * * \\
\mathrm{CO}_{2}\end{array}$ & $\begin{array}{l}4.4 \\
4.6 \\
0\end{array}$ & $\begin{array}{l}124 \\
178 \\
159\end{array}$ \\
\hline $\begin{array}{l}11 \\
23 \\
24\end{array}$ & -1 & -1 & -1 & -1 & $\begin{array}{l}\mathrm{HNO}_{3} \text { * } \\
\mathrm{HNO}_{3} * * \\
\mathrm{CO}_{2}\end{array}$ & $\begin{array}{l}0.5 \\
0.2 \\
0\end{array}$ & $\begin{array}{l}26 \\
38 \\
32\end{array}$ \\
\hline $\begin{array}{l}13 \\
25 \\
26\end{array}$ & -1 & -1 & +1 & +1 & $\begin{array}{l}\mathrm{HNO}_{3} \text { * } \\
\mathrm{HNO}_{3} \text { ** } \\
\mathrm{CO}_{2}\end{array}$ & $\begin{array}{l}0 \\
0.2 \\
0\end{array}$ & $\begin{array}{l}2.2 \\
2.4 \\
2.4\end{array}$ \\
\hline
\end{tabular}

TMilliliters of $7.5 \mathrm{M} \mathrm{HNO}_{3}$ added per $100 \mathrm{~mL}$ of slurry. *Test results from initial runs listed in Table III.

** Repeat runs using nitric acid.

\section{other observations}

Several other measurements were made during the tests, including total soluble boron, $\mathrm{pH}$, soluble organics, and soluble metals (i.e., $\mathrm{Cu}, \mathrm{Ag}, \mathrm{Ru}, \mathrm{Rh}$, and Pd). The analytical results are listed in Appendix $A$ and summarized briefly in the following paragraphs.

\section{Total Soluble Boron}

If KTPB decomposes to yield soluble $\mathrm{K}^{+}$and soluble boroncontaining products, then the rate of appearance of boron in solution should equal the rate of appearance of potassium. An increase in soluble boron confirms that the reaction includes decomposition of tetraphenylborate since other analyses show that tetraphenylborate is not accumulating in solution. Table VI lists the changes in potassium and boron for five of the runs. There is a strong correlation between the change in boron and potassium, although the yield of boron is slightly greater than expected. The difference could be due to either analytical bias in the potassium and boron measurements or the presence (and simultaneous decomposition) of solid NaTPB. The discrepancy was small and its source will be pursued in future work.

\section{Benzene}

Benzene from the decomposition reaction was measured in a few cases to confirm that the potassium found in solution indicated loss of tetraphenylborate. The analytical method 
TABLE VI. Comparison of Yields of Soluble Potassium and Boron

$\begin{array}{rcc}\text { Run * } & \text { Change } & \text { (mmoles } \\ & {\underline{\mathrm{K}^{+}}}^{+} & \underline{\mathbf{B}} \\ 4 & 88 & 110 \\ 5 & 7.9 & 13.9 \\ 10 & 1.5 & 4.7 \\ 11 & 37 & 47 \\ 12 & 25 & 34\end{array}$

*Difference between initial and final measurements on filtered samples. The elapsed time was 56 days. ** See Tables IV and V.

\section{TABLE VII. Benzene Yields}

\begin{tabular}{llcc} 
Run $^{*}$ & \multicolumn{2}{c}{ Change in Concentration } & $\begin{array}{c}\text { (mmoles/L) ** } \\
\text { Benzene }\end{array}$ \\
25 & repeat of Run 13 with $\mathrm{HNO}_{3}$ & $\frac{1.6}{2}$ & $\frac{0.2}{1.6}$ \\
26 & repeat of Run 13 with $\mathrm{CO}_{2}$ & 1.6 & 0.01 \\
19 & repeat of Run 3 with $\mathrm{HNO}_{3}$ & 16. & 0.7 \\
20 & repeat of Run 3 with $\mathrm{CO}_{2}$ & 14. & 4. \\
23 & repeat of Run 11 with $\mathrm{HNO}_{3}$ & 20. & 12. \\
24 & repeat of Run 11 with $\mathrm{CO}_{2}$ & 23. & 12. \\
21 & repeat of Run 4 with $\mathrm{HNO}_{3}$ & 42. & 280 \\
22 & repeat of Run 4 with $\mathrm{CO}_{2}$ & 66. & 320
\end{tabular}

*From Table V.

**Changes calculated between initial and 27-day samples.

used for benzene is known to be inaccurate, but it can show trends if the differences between samples are large. ${ }^{18}$ Table VII lists the results for the eight repeat experiments listed in Table V. Benzene concentrations increase with the amount of $\mathrm{K}^{+}$found in solution (Table VII). In the six slowest reactions, the amount of benzene produced was less than expected from the theoretical yield of four moles of benzene per mole of potassium. In the two fastest reactions (Runs 21 and 22), more than the theoretical yield of benzene was measured. These results could be due to errors in the benzene measurements, loss of small amounts of benzene from the reaction container, contribution from the decomposition of NaTPB, or to a change in reaction stoichiometry between slow and fast reactions.

Solution $\mathrm{pH}$.

The $\mathrm{pH}$ of the solutions changed very little during the test. In most cases, the $\mathrm{pH}$ varied randomly by $\pm 0.25 \mathrm{pH}$ units, with 
only one varying by more than $0.5 \mathrm{pH}$ units. In Run 8 , the $\mathrm{pH}$ decreased by $1.1 \mathrm{pH}$ units from 12.0 to 10.9. The large change may reflect the $200 \mathrm{Mrad}$ radiation dose that the slurry received prior to the test. Large radiation doses are known to cause the $\mathrm{pH}$ to decrease, although the change typically is observed within a few days after receiving the dose. ${ }^{13}$

Soluble organics (NaTPB, 3PB, 2PB, 1PB, and phenol). One or more of the phenyl borate decomposition products (i.e., 3PB, 2PB, and 1PB) promote the rapid decomposition of soluble $\mathrm{TPB}^{-}{ }^{10}$ Since these compounds may also promote the decomposition of solid tetraphenylborates, the following target values for the initial test conditions were set: $3 \mathrm{~PB}$, $500 \mathrm{mg} ; 2 \mathrm{~PB}$ and $1 \mathrm{~PB}, 250 \mathrm{~g} / \mathrm{L}$. Phenol was also targeted for $250 \mathrm{mg} / \mathrm{L}$ but a report subsequent to the start of these tests found that phenol does not affect the catalytic reaction. ${ }^{7}$ In 22 of the 29 experiments reported in this document, one of the three phenyl borate compounds was more than $20 \%$ below the target. In one case (i.e., Run 26), two compounds were more than $20 \%$ below the target. In those cases where the experiments were repeated, the variation in starting concentrations does not appear to have significantly affected the final rate. In almost all runs, the rate of appearance of soluble $\mathrm{K}^{+}$was linear from the start, even though the concentrations of the phenyl borate compounds varied drastically. This result implies that although some amount of at least one of the phenyl borate compounds is required to initiate the decomposition reaction, it does not appear important in sustaining the reaction. Therefore, the variation in the starting concentrations probably did not affect the measured rates. However, this conclusion should be revisited when the identity and role of the significant phenyl borate compounds are determined. The lack of precision in achieving the target values was due to formation of the intermediates by irradiation (yielding values higher than target), formation and destruction during the $\mathrm{pH}$ adjustment step (yielding high and low values), and inaccuracies in adding small amounts of the compounds during slurry preparation. Future preparations will include steps to minimize these sources of error.

The other organics (3PB, 2PB, and 1PB) typically decreased during the tests. In all but one case, 3PB disappeared completely by the fourth week. The $2 \mathrm{~PB}$ and $1 \mathrm{~PB}$ concentrations typically decreased, but in most cases they were still present in measurable amounts after four weeks. The rapid loss of $3 \mathrm{~PB}$ is unexpected from previous measurements of the $3 \mathrm{~PB}$ reaction rate. ${ }^{19}$ If $3 \mathrm{~PB}$ is produced but does not accumulate, it must be decomposing at least as fast as the tetraphenylborate. Based on the rate of loss of tetraphenylborate and the previously measured rate constants for $3 \mathrm{~PB}$, the $3 \mathrm{~PB}$ concentration should be observable in many of the 
experiments. The increase in soluble boron indicates that $3 \mathrm{~PB}$ is not precipitating as it forms. The missing $3 \mathrm{~PB}$ suggests that either the decomposition of tetraphenylborate occurs by concerted loss of two phenyl groups bypassing 3PB and forming $2 \mathrm{~PB}$ directly, or the estimated rate constants for decomposition of $3 \mathrm{~PB}$ are too low. The concerted loss of two phenyl groups is unlikely since the decomposition of soluble $\mathrm{TPB}^{-}$does not proceed by that mechanism. It is more likely that extension of the $3 \mathrm{~PB}$ rate constants (measured at $0.5 \mathrm{M}$ $\mathrm{NaOH}$ or higher) to the low $\mathrm{pH}$ used in the solids stability tests may introduce significant error.

Phenol concentrations increased in the majority of the tests and remained constant in the others. This is expected since phenol does not decompose or decomposes slowly in the presence of radiation. The phenol yields (normalized to loss of tetraphenylborate) are generally low for the rapid decomposition reactions and higher for slow decomposition reactions. Low phenol yields imply benzene is the major product similar to Tank $48 \mathrm{H}$ experience. ${ }^{3}$

Transition Metals.

Transition metals were measured in the aqueous phase at the beginning and end of the test using Inductively coupled Plasma Mass Spectrometry (ICP-MS). Consistent trends were not observed. Since the initial samples were obtained within a few hours of mixing the metals into the slurries, the solutions probably had not reached equilibrium. Therefore, changes in metals between the start and end may only reflect attainment of equilibrium. Each metal was found to increase in some cases and decrease in others, but instances where the metals increased in solution predominated. One possibly significant observation was that for palladium, all four of the fastest reactions showed decreases in the soluble Pd. This could reflect either adsorption on solids or extraction into a nonaqueous phase bound to the solids.

\section{Modeling Results}

The appearance of soluble potassium was predicted for the conditions in the first fourteen tests in Tables III and IV using the dual mechanism model described previously. ${ }^{1}$ The model includes two decomposition pathways: radiolytic and catalytic. Table VIII lists the values of parameters used in the modeling calculations. The results of the calculations are plotted along with the experimental data in Figure 1.

The two-mechanism model predicts slower rates of increase in soluble potassium than measured in ten of the 14 tests modeled. The model worked only for those tests that showed very little reactivity. This result strongly suggests an additional mechanism for decomposition, or that one of the two mechanisms already included is incorrectly formulated. 
TABLE VIII. Values of Parameters Used in Modeling Calculations

\begin{tabular}{ccccccc} 
Run & $\begin{array}{c}\mathrm{k} \\
\left(\mathrm{h}^{-1}\right)\end{array}$ & $\begin{array}{c}\mathrm{K}_{1} \\
\left(\mathrm{molar}^{2}\right)\end{array}$ & $\begin{array}{c}\mathrm{K}_{2} \\
\left(\mathrm{molar}^{2}\right)\end{array}$ & $\begin{array}{c}\mathrm{R} \\
(\mathrm{eV} / \mathrm{s})\end{array}$ & $\begin{array}{c}\text { Initial } \\
\text { NaTPB } \\
(\operatorname{mmolar})\end{array}$ & $\begin{array}{c}\mathrm{K}^{+} \\
(\mathrm{mmolar})\end{array}$ \\
1 & 1.5 & $5.34 \mathrm{E}-10$ & $9.68 \mathrm{E}-13$ & 0 & 0.11 & - \\
2 & 1.5 & $5.34 \mathrm{E}-10$ & $9.68 \mathrm{E}-13$ & $2.56 \mathrm{E} 21$ & 0.21 & - \\
3 & 1.5 & $5.34 \mathrm{E}-10$ & $9.68 \mathrm{E}-13$ & $2.56 \mathrm{E} 21$ & - & 1.2 \\
4 & 1.5 & $5.34 \mathrm{E}-10$ & $9.68 \mathrm{E}-13$ & 0 & - & 1.3 \\
5 & 0.1 & $8.64 \mathrm{E}-9$ & $1.57 \mathrm{E}-11$ & $1.25 \mathrm{E} 21$ & - & 3.5 \\
6 & 0.1 & $8.64 \mathrm{E}-9$ & $1.57 \mathrm{E}-11$ & $1.25 \mathrm{E} 21$ & - & 3.2 \\
7 & 0.1 & $8.64 \mathrm{E}-9$ & $1.57 \mathrm{E}-11$ & $1.25 \mathrm{E} 21$ & - & 3.0 \\
8 & 0.1 & $8.64 \mathrm{E}-9$ & $1.57 \mathrm{E}-11$ & $1.25 \mathrm{E} 21$ & - & 10.5 \\
9 & 0.005 & $6.60 \mathrm{E}-8$ & $1.20 \mathrm{E}-10$ & $2.16 \mathrm{E} 21$ & 1.20 & - \\
10 & 0.005 & $6.60 \mathrm{E}-8$ & $1.20 \mathrm{E}-10$ & 0 & 0.97 & - \\
11 & 0.004 & $1.41 \mathrm{E}-7$ & $2.55 \mathrm{E}-10$ & 0 & 0.90 & - \\
12 & 0.004 & $1.41 \mathrm{E}-7$ & $2.55 \mathrm{E}-10$ & 0 & 0.90 & - \\
13 & 0.004 & $1.41 \mathrm{E}-7$ & $2.55 \mathrm{E}-10$ & $2.10 \mathrm{E} 21$ & 0.81 & - \\
14 & 0.004 & $1.41 \mathrm{E}-7$ & $2.55 \mathrm{E}-10$ & $2.10 \mathrm{E} 21$ & 0.96 & - \\
\hline
\end{tabular}

The results do not suggest a synergistic effect between the two mechanisms, since the model also predicts lower rates than measured in tests that did not include radiation (Runs 1,11 , and 12).

The rate constants shown in Table VIII were derived from experiments on the decomposition of soluble TPB ${ }^{-6,9}$ The rates were corrected for the higher sludge and catalyst concentration in these tests by assuming the rate proportional to the weight of sludge and catalyst added.

The solubility constants for KTPB and CSTPB were calculated as described previously. ${ }^{1}$

The radiation dose to the solids was calculated differently than the method used in previous tests with radioactive slurries. In the present tests, the radiation source was external to the samples so the entire sample was irradiated in a uniform field. No correction is necessary for separation of the solids by settling or floating. The fraction of the total dose adsorbed by the solids was assumed to equal the weight Eraction of the solids (either 5\% or $2.5 \%)$.

\section{statistical Analysis}

The results of the 18 tests listed in Table III and the eight repeat tests listed in Table IV were statistically analyzed with the details described in Appendix B. The following observations summarize the statistical analysis. 
- The best linear model using all of the data (including the highest, or "accelerated" rate measurements) was:

$$
\begin{aligned}
\mathrm{K}^{+} \text {rate }= & 166.0+11.70\left[\mathrm{Na}^{+}\right]-12.7[\mathrm{pH}] \\
& +0.016[\text { Total dose }]-0.00188[\text { Dose rate] }
\end{aligned}
$$

where $\mathrm{K}^{+}$rate $=$rate of increase in soluble $\mathrm{K}^{+}(\mathrm{mg} / \mathrm{L} /$ day $)$

$\left[\mathrm{Na}^{+}\right]=$total sodium ion concentration (molar)

$[\mathrm{pH}]=$ hydrogen ion concentration (pH units)

[Total dose] = pre-test adsorbed dose (Mrad)

[Dose rate] = continuous dose rate during test $(\mathrm{rad} / \mathrm{h})$

- Low $\mathrm{pH}$ and high sodium ion concentration were significant factors in promoting the appearance of soluble $\mathrm{K}^{+}$.

- Continuous radiation dose rate during the tests was a significant factor in retarding the appearance of soluble $\mathrm{K}^{+}$.

- Pre-test irradiation was not a significant factor in predicting the rate of appearance of soluble $\mathrm{K}^{+}$.

- The fit of this model to the data was not good. The $\mathrm{R}^{2}$ measure of fit was 0.58 .

- Other, non-linear dependencies on $\left[\mathrm{Na}^{+}\right]$and $\mathrm{pH}$ did not significantly improve the fit (i.e., $\exp \left(\left[\mathrm{Na}^{+}\right]^{1 / 2}\right),\left[\mathrm{OH}^{-}\right]$, and $\left.\left[\mathrm{OH}^{-}\right]^{-1}\right)$.

The absence of a good fit to the data suggests that the rate is either affected by an additional factor not kept constant during these tests, or the dependence of the potassium rate is more complicated than the linear and non-linear models examined in the statistical analysis.

\section{Effects of Other Variables}

\section{Effect of sludge concentration}

The rate of appearance of soluble potassium is directly proportional to the concentration of sludge and noble metal catalysts. Table IX and Figure 2 show the results of separate experiments in which the effect of sludge concentration was measured at $0.24,1.2$, and $2.4 \mathrm{~g}$ of sludge per liter of slurry. The total ruthenium, rhodium, and palladium in the slurries increased in proportion to the sludge. The graph of the rate constant and sludge concentration (Fig. 2) shows that the relationship is approximately linear in the range tested with an intercept near zero, as expected when the sludge and metal catalysts are absent. 
TABLE IX. Effect of sludge Concentration*

Sludge

$\mathrm{Ru}$

$\mathrm{Rh}$

Pd

$\mathrm{K}^{+}$Rate

$(\mathrm{g} / \mathrm{L}) *$

$(\mathrm{mg} / \mathrm{L})(\mathrm{mg} / \mathrm{L})(\mathrm{mg} / \mathrm{L})$

(mg/L/day)

0.24

1.2

6.3

1.7

3.2

0.11

28.4

7.4

13.7

56.0

14.6

26.9

8.5

11.9

*Other significant conditions: temperature, $45{ }^{\circ} \mathrm{C}$; 5 wt $\%$ KTPB, $4.5 \mathrm{M} \mathrm{Na}^{+}$. The sludge concentrations are approximately $0.2,1$ and 2 wt $\%$ of the slurry.

\section{FIGURE 2. Effect of sludge and Noble Metals on Tetraphenylborate Decomposition Rate}

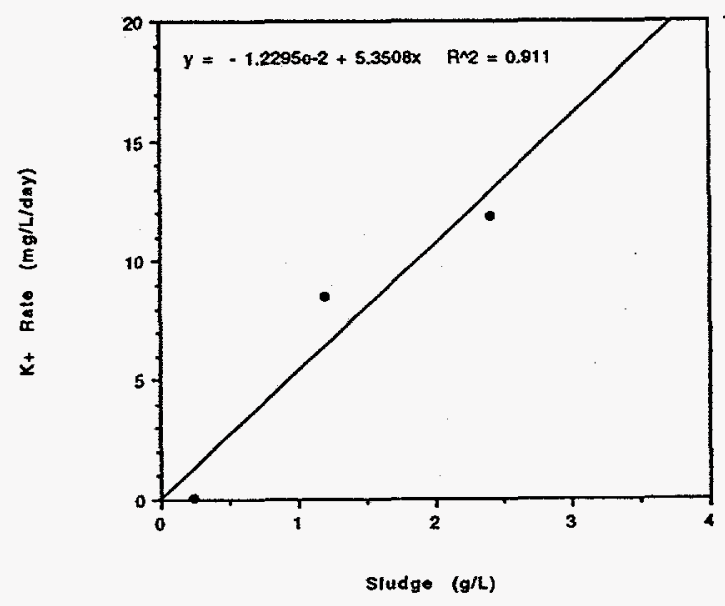

Experiments on the decomposition of soluble tetraphenylborate used 0.2 wt $\%$ sludge similar to the amount in Tank 48H during ITP first batch operations. ${ }^{3}$ Previous solids stability Eests with radioactive waste and simulated slurries used 0.2 to 0.9 wt $\%$ sludge. ${ }^{1}$ A sludge concentration of 1 wt $\%$ was used in the statistically designed tests.

\section{Effect of pH}

Increasing the $\mathrm{pH}$ of the slurry decreases the rate of the decomposition of potassium tetraphenylborate. The two midpoint tests at $\mathrm{pH} 12$ (Runs 5 and 6 , Table IV) were repeated at $\mathrm{pH} 10$ (Runs 14 and 15, Table IV) to directly determine the effect of $\mathrm{pH}$ in the absence of changes in other variables. The rate of decomposition of KTPB more than doubles when the $\mathrm{pH}$ decreases from 12 to 10. The results agree with the results of the statistical analysis of all of the data. 


\section{Uranium}

Addition of uranyl nitrate to simulate the uranium in sludge increased the rate of appearance of potassium by $30 \%$. This is shown by comparing Runs 5 and 6 to Run 7 in Table IV. Although significant compared to the reproducibility of the duplicate centerpoints (Run 5 and Run 6), it is a minor effect compared to salt concentration and $\mathrm{pH}$. The relative insensitivity to uranium is also true of the reaction of soluble TPB $^{-}{ }^{11}$

\section{Very High Radiation Dose}

A large absorbed radiation dose significantly reduces the rate of appearance of soluble potassium. This is shown by comparing Runs 5 and 6 to Run 8 in Table IV. The 200 Mrad dose reduced the rate of appearance of potassium by $80 \%$ compared to a dose of $15 \mathrm{Mrad}$. Thus, the absorbed dosed received by the precipitate during extended outages in Tank $48 \mathrm{H}$ will decrease the rate of catalytic decomposition.

\section{Nitrogen Inerting}

Nitrogen inerting reduced the rate of decomposition by $35 \%$ in the one test in which the effect was measured. This is shown by comparing Run 11 with Run 12. This result supports the assertion that tests run under air yield conservatively high reaction rates compared to inerted tests.

\section{KTPB Solids Concentration}

Reducing the concentration of KTPB solids from 5 to 2 wt $\%$ did not significantly change the rate of appearance of potassium. This is shown by comparing Run 13 with Run 14 . Although the reaction rate for the 2.5 wt $\%$ slurry was $10 \%$ slower, this weak dependence on a primary reactant is smaller than expected.

\section{RECOMMENDATIONS FOR FURTHER ACTIVITIES}

The results of the experiments and modeling suggest the following additional areas of investigation.

- Determine the rate of decomposition under compositions more closely related to expected ITP operating conditions.

The range of variables used in the statistically designed experiment were chosen to maximize the composition space investigated while assuming that high decomposition rates were largely caused by higher temperatures. The results suggest that combinations of low $\mathrm{pH}$ and high sodium that will not occur in the ITP process also cause high decomposition rates. 
- Determine the catalytically active components for the decomposition reaction.

The design of the present set of tests was based on the assumption that the catalytic system for loss of KTPB solids is the same as for the decomposition of soluble NaTPB. This should be verified to insure that the proper variables are controlled in future tests. The test methodology would be similar to the catalyst identification tests for soluble NaTPB. If the catalytic system is similar, then the test series could be considerably shortened compared to the earlier work.

- Determine the phase in which the metal catalyst acts.

Assuming that the catalyst system for the decomposition of KTPB is similar to soluble NaTPB, knowledge of the location of the catalyst metal can help determine if the right variables are being controlled in the tests.

- Determine the relative decomposition rates for potassium and sodium tetraphenylborate solids.

A major feature of the Tank $48 \mathrm{H}$ reaction was the rapid decomposition of NaTPB (soluble and excess solids) but not the KTPB. The KTPB solids appear to decompose at a slow rate attributable to radiolysis. The difference in stability of the two compounds towards the catalytic decomposition reaction should be experimentally established to help explain why the Tank $48 \mathrm{H}$ reaction did not consume the KTPB.

- Investigate other statistical models.

The linear model described in this document is a good starting place when other information about the reacting system is absent. Additional testing will reveal the functional dependence for each variable which will lead to a more accurate model.

\section{REFERENCES}

1. D. D. Walker, "Tetraphenylborate Solids stability Tests (U)," WSRC-TR-97-0185, Rev.0, June 25, 1997.

2. D. D. Walker, M. J. Barnes, C. L. Crawford, R. F. Swingle, R. A. Peterson, M. S. Hay, and S. D. Fink, "Decomposition of Tetraphenylborate in Tank 48H (U)," WSRC-TR-96-0113, Rev.0, May, 10, 1996.

3. D. D. Walker and C. A. Nash, "Results from Tank 48H Slurry Decontamination and Decomposition Experiments in Support of 
ITP Process Verification Testing (U)," WSRC-TR-96-0190, September 6, 1996.

4. J. R. Fowler and R. A. Jacobs, "Projected Variation in Feeds to the In-Tank Precipitation Process (U)," OPS-DTZ-970004, January 27, 1997.

5. J. R. Fowler, "Sludge Composition for Each Tank and DWPF Feed Batches," (U), DPST-84-556, June 11, 1984.

6. M. J. Barnes, "Sodium Tetraphenylborate Catalyst Identification: Preliminary Studies Set 2 (U)," WSRC-TR-970144, Rev.0, May 28, 1997.

7. M. J. Barnes and R. A. Peterson, "Sodium Tetraphenylborate Catalyst Identification: Phase A Statistical Design Studies (U)," WSRC-TR-97-0210, Rev.0, July 22, 1997.

8. M. L. Hyder, "The Role of Oxygen in the Copper-Catalyzed Decomposition of Phenyl Borates in Aqueous Alkaline Solutions (U) ," WSRC-TR-97-0069, March 17, 1997.

9. M. J. Barnes, C. L. Crawford, and C. A. Nash, "Sodium Tetraphenylborate Catalyst Identification: Preliminary Studies Set 1 (U),"WSRC-TR-97-0060, Rev.0, March 6, 1997.

10. M. J. Barnes and R. A. Peterson, "Sodium Tetraphenylborate Catalyst Identification: Phase B and C Statistical Design Studies (U),"WSRC-TR-97-0230, Rev.0, August 13, 1997.

11. M. J. Barnes, "Sodium Tetraphenylborate Catalyst Identification: Phase D Statistical Design Studies (U)," WSRC-TR-97-0275, Rev.0, September 5, 1997.

12. C. L. Crawford, "Decomposition Studies of

Tetraphenylborate Slurries (U)," WSRC-TR-97-0046, Rev.0,-May, $6,1997$.

13. D. D. Walker and J. P. Doherty, "The Effects of Gamma Irradiation on the Rheology of KTPB Slurries," (U), DPST-85926, November 5, 1985.

14. D. J. McCabe, "Cesium, Potassium, and Sodium Tetraphenylborate Solubility in Salt Solution (U)," WSRC-TR96-0384, Rev.0, December 16, 1996.

15. J. R. Fowler, "Acid Hydrolysis of Tetraphenylborate at Elevated Temperature and Pressure," (U), DPST-82-555, May 27, 1982 .

16. Westinghouse Savannah River Company, "WSRC-241-82H Control Room Process Requirements (U)," WSRC-IM-91-63, Rev.18, July, 1997. 
17. D. T. Hobbs, "Concentrations of Metals and Non-Metals in Alkaline Waste Slurries (U),"WSRC-TR-96-0058, Rev.0, April 3, 1996.

18. D. D. Walker, W. T. Boyce, C. J. Coleman, D. P Diprete, T. B. Edwards, A. A. Ekechukwu, C. W. Hsu, S. F. Peterson, L. L. Tovo, and M. J. Whitaker, "Tank 48H Waste Composition and Results of Investigations of Analytical Methods (U)," WSRCTR-97-0063, Rev.0, Apri1 2, 1997.

19. R. A. Peterson and T. B. Edwards, "Statistical Investigation into the Decomposition Rates of Tetraphenylborate and its Daughter Compounds (U)," WSRC-TR97-00403, Rev.0, December 1997.

20. L. L. Tovo and W. T. Boyce, "Analysis of Copper in the In-Tank Precipitation Process Caustic Samples (U)," WSRC-TR96-0400, December 12, 1996.

21. N. E. Bibler, "Calibration of Intense Co-60 Gamma Ray Sources at the Savannah River Plant," (U), DP-1414, May 1976. 


\section{APPENDIX A}

Experimental

\section{Preparation of slurries}

Researchers prepared six simulated KTPB slurries (nominally 2.5 or 5 wt $\%$ ) with the compositions shown in Table A-1. The statistically designed tests used Slurries A through E. The repeat tests investigating the effect of the $\mathrm{pH}$ adjustment method and additional low pH tests used second batches of the slurries. The experiment measuring the effect of sludge and noble metals concentration used Slurry F. Researchers precipitated the KTPB in the presence of a low sodium ion concentration with the soluble sodium salts added after precipitation. Researchers prepared the $0.1 \mathrm{M} \mathrm{Na}^{+}$Slurry $\mathrm{E}$ at 2.5 wt $\%$ solids, then concentrated to 5 wt $\%$ solids.

Researchers irradiated all or portions of the slurries (except Slurry F) in Co-60 gamma sources at the dose rates and to the doses listed in Table A-2. After irradiation, the slurries were analyzed for potassium ion and adjusted with $0.55 \mathrm{M}$ NaTPB solution $(0.5$ to $8.6 \mathrm{~mL})$ to obtain TPB ion in solution. On the day the test began, $100 \mathrm{~mL}$ portions of slurry were placed in Erlenmeyer flasks. The components of the catalyst system were added next (Table A-3). Since some potassium was present in the catalyst components, another small addition of $0.55 \mathrm{M}$ NaTPB solution was made (approximately $0.3 \mathrm{~mL}$ ). The slurries were stirred at room temperature for one hour, then the $\mathrm{pH}$ of each was adjusted. During the initial tests, the pH adjustment used nitric acid or sodium hydroxide. During the repeat tests, either nitric acid or carbon dioxide was used. Carbon dioxide was obtained from evaporating dry ice. The amounts of nitric acid or sodium hydroxide required for the adjustments are shown in Table $\mathrm{A}-2$. The $\mathrm{pH}$ adjustment step was not required for the

\begin{tabular}{cccrrrrr} 
TABLE A-1. & Simulant & slurry & \multicolumn{3}{c}{ Compositions } \\
Component & A & B & C & D & E & F \\
\hline KTPB $(g / L)$ & 60 & 60 & 60 & 60 & 30 & 60 \\
$(\sim \mathrm{wt} \%)$ & 5 & 5 & 5 & 5 & 2.5 & 5
\end{tabular}

$\begin{array}{lllllll}\mathrm{Na}^{+} & 5.5 & 5.5 & 2.8 & 0.65 & 0.1 & 4.5 \\ \mathrm{OH}^{-} & 3.0 & <.01 & 0.01 & 0.50 & <.01 & 2.6 \\ \mathrm{NO}_{3}{ }^{-} & 1.36 & 3.00 & 1.51 & 0.15 & 0.075 & 0.64 \\ \mathrm{NO}_{2}{ }^{-} & 0.50 & 1.10 & 0.56 & - & - & 0.69 \\ \mathrm{AlO}^{-} & 0.21 & 0.47 & 0.24 & - & - & 0.17 \\ \mathrm{CO}_{3}{ }^{2-} & 0.10 & 0.22 & 0.11 & 0.25 & - & 0.17 \\ \mathrm{SO}_{4}^{2-} & 0.093 & 0.20 & 0.10 & - & - & 0.009 \\ \mathrm{Cl}^{2} & 0.016 & 0.036 & 0.018 & - & - & 0.013 \\ \mathrm{~F}^{-} & 0.010 & 0.022 & 0.011 & - & - & 0.007 \\ \mathrm{PO}_{4}{ }^{3-} & 0.006 & 0.014 & 0.007 & - & - & 0.006\end{array}$


TABLE A-2. Slurry Irradiation and pH Adjustment

Slurry Composition* Total Dose pH Adjustment (target)

1
2
3
4
5
6
7
8
9
10
11

A

A

B

B

C

c

C

D

D

E

12

13

14

15

16

17

18

19

20

21

22

22

24

25

26

27

28

29

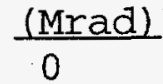

30

0

30

15

15

15

15

0

30

0

0

30

30

15

15

15

15

0

30

30

0

0
30
30

30

0
0
0 none required

none required

$4.85 \mathrm{~mL}$ of $7.5 \mathrm{M} \mathrm{HNO}_{3} \quad(\mathrm{pH} 10)$

$4.35 \mathrm{~mL}$ of $7.5 \mathrm{M} \mathrm{HNO}_{3}(\mathrm{pH} 10)$

$1.25 \mathrm{~mL}$ of $7.5 \mathrm{M} \mathrm{HNO}_{3}$ (pH 12)

$1.25 \mathrm{~mL}$ of $7.5 \mathrm{M} \mathrm{HNO}_{3}(\mathrm{pH} 12)$

$1.50 \mathrm{~mL}$ of $7.5 \mathrm{M} \mathrm{HNO}_{3}(\mathrm{pH} 12)$

$2.70 \mathrm{~mL}$ of $4 \mathrm{M} \mathrm{NaOH}$ (pH 12)

none required

$\left(0.5 \mathrm{M} \mathrm{OH}^{-}\right)$

none required

$\left(0.5 \mathrm{M} \mathrm{OH}^{-}\right)$

$0.5 \mathrm{~mL} / 7.5 \mathrm{M} \mathrm{HNO}_{3}$ and $0.1 \mathrm{~mL}$ of $4 \mathrm{M} \mathrm{NaOH}$

$(\mathrm{pH} 10)$

$0.25 \mathrm{~mL} / 7.5 \quad \mathrm{M} \mathrm{HNO}_{3}$ and $0.1 \mathrm{~mL}$ of $4 \mathrm{M} \mathrm{NaOH}$

(pH 10)

$0.5 \mathrm{~mL}$ of $4 \mathrm{M} \mathrm{NaOH}$

none required

$(\mathrm{pH} 10)$

(pH 10)

$\mathrm{CO}_{2}$

$\mathrm{CO}_{2}$

$\mathrm{CO}_{2}$

$\mathrm{CO}_{2}$

(pH 10)

(pH 10)

(pH 10)

(pH 10)

$5.0 \mathrm{~mL}$ of $7.5 \mathrm{M} \mathrm{HNO}_{3}$ (pH 10)

$\mathrm{CO}_{2} \quad(\mathrm{pH} 10)$

$4.6 \mathrm{~mL}$ of $7.5 \mathrm{M} \mathrm{HNO}_{3} \quad(\mathrm{pH} 10)$

$\mathrm{CO}_{2}$

(pH 10)

$0.25 \mathrm{~mL}$ of $7.5 \mathrm{M} \mathrm{HNO}_{3}(\mathrm{pH} 10)$

$\mathrm{CO}_{2}$

$0.25 \mathrm{~mL}$ of $7.5 \mathrm{M} \mathrm{HNO}_{3}$

(pH 10)

$\mathrm{CO}_{2}$

(pH 10)

(pH 10)

none required

(2.6 $\left.\mathrm{M} \mathrm{OH}^{-}\right)$

none required

none required

$\left(2.6 \mathrm{M} \mathrm{OH}^{-}\right)$

$\left(2.6 \mathrm{M} \mathrm{OH}^{-}\right)$

* See Table A-1. 
TABLE A-3. Catalyst Components in simulant slurries

Insoluble Components (wt $\%$ of slurry)*

$1.2 \mathrm{~g} / \mathrm{L}(\sim 1$ wt $\%)$ sludge

$1.2 \mathrm{~g} / \mathrm{L}\left(\sim 1\right.$ wt $\left.\frac{0}{\circ}\right)$ monosodium titanate

Sludge composition (wt \% of dry sludge):

$\begin{array}{lcll}\mathrm{Al} & 4.8 & \mathrm{Cu} & 0.1 \\ \mathrm{Fe} & 18.8 & \mathrm{Mg} & 0.1 \\ \mathrm{Mn} & 5.9 & \mathrm{Ni} & 2.5 \\ \mathrm{Ru} & 0.23 & \mathrm{~Pb} & 0.3 \\ \mathrm{Pd} & 0.11 & \mathrm{Zn} & 0.2 \\ \mathrm{Rh} & 0.06 & \mathrm{Zr} & 2.5 \\ \mathrm{Cr} & 0.2 & & \end{array}$

Metal Additives (mg/L)

\begin{tabular}{|c|c|c|c|c|c|}
\hline $\mathrm{Ca}(\mathrm{II})$ & 12.2 & $\mathrm{Ru}$ (III) & 0.8 & $c d(I I)$ & 0.4 \\
\hline $\operatorname{Sr}(I I)$ & 0.1 & Co (II) & 0.04 & $\mathrm{Hg}$ (II) & 2.2 \\
\hline La (III) & 0.05 & $R h$ (III) & 0.2 & $S \vec{i}(I V)$ & 16 \\
\hline $\mathrm{Ce}$ (IV) & 0.3 & $\mathrm{Pd}(I I)$ & 0.4 & $\operatorname{Sn}(I I I)$ & 2.1 \\
\hline $\mathrm{Cr}$ (VI) & 60 & $\mathrm{Cu}$ (II) & 1.7 & $\mathrm{~Pb}(I I)$ & 1.2 \\
\hline Mo (VI) & 12. & $\operatorname{Ag}(I)$ & 0.6 & As (IV) & 0.04 \\
\hline $\mathrm{Fe}$ (III) & 2.6 & $\mathrm{Zn}(I I)$ & 8.8 & Se (VI) & 1 \\
\hline
\end{tabular}

Organic Additives (mg/L)

$\begin{array}{lllr}3 \text { PB } & 500 & \text { Diphenylmercury } & 150 \\ \text { 2PB } & 250 & \text { Methanol } & 4 \\ \text { Phenol } & 250 & \text { Isopropanol } & 40 \\ \text { Benzene } & 750 & & \end{array}$

* The experiment measuring the effect of sludge and noble metals concentration used $0.2,1.0$, and 2.0 wt $\%$ of these components (sludge and monosodium titanate). The other components were not varied.

experiment measuring the effect of sludge and noble metal concentration (Slurry F). Approximately $65 \mathrm{~mL}$ of slurry were placed in $70-\mathrm{mL}$ glass serum bottles. Uranyl nitrate (51 $\mathrm{mg})$ was added to Slurry 7 and all the vials were capped. The vapor space above Slurry 12 was flushed gently with nitrogen for 5 minutes. The vials were then placed in an oven or thermostated Co-60 gamma irradiation source at $45{ }^{\circ} \mathrm{C}\left( \pm 3{ }^{\circ} \mathrm{C}\right)$. The gamma source contained two shelves, once of which was partially shielded. The dose rates for the two shelves were $1.5 \times 10^{4}$ and $2.8 \times 10^{4} \mathrm{rad} / \mathrm{h}$. The vials were sampled by syringe once a week for eight weeks. The samples were filtered using disposable nitrocellulose filters $(0.45$ micron nominal pore size).

\section{Analytical Results}

The filtered samples were analyzed for potassium ion, organic compounds (NaTPB, 3PB, 2PB, 1PB, and phenol), and pH. A few 
WSRC-TR-97-0285 Rev.0

Page 33 of 44

filtrate samples were analyzed for total boron and a few slurry samples were analyzed for benzene. The initial and Einal filtrate samples were also analyzed for the potentially catalytic metals ( $\mathrm{Cu}, \mathrm{Ag}, \mathrm{Ru}, \mathrm{Rh}$, and $\mathrm{Pd}$ ). The analytical results from all experiments are listed in Table A-4.

Several of the initial samples showed high results for both $\mathrm{K}^{+}$ and NaTPB, in excess of the amount expected from the solubility of KTPB. Analyses of two of these initial samples (Runs 4 and 8 ) were repeated six weeks later along with one initial sample (Run 12) in which the potassium and NaTPB appeared consistent with the solubility of KTPB. Table A-5 summarizes the results. The repeat analyses confirmed the original potassium results but failed to confirm the high NaTPB results. Soluble NaTPB is relatively stable once it is separated from the precipitate and sludge solids, as shown by the results of the Run 12 sample (no loss of NaTPB in 6 weeks). The loss of NaTPB was not reflected by increases in $3 \mathrm{~PB}$ and $2 \mathrm{~PB}$, although they might have decomposed also. No precipitate was observed in the stored samples indicating that the decrease in NaTPB was not caused by precipitation of KTPB during storage (also confirmed by the fact that $\mathrm{K}^{+}$did not change). The initial $\mathrm{K}^{+}$results agree with the trend in potassium shown in subsequent samples. These results imply the NaTPB results were erroneously high.

\section{Analytical Methods}

The following analyses were performed by the Analytical Development Section of SRTC.

Phenylboronic acid (1PB) and phenol were measured by high performance liquid chromatography (HPLC) on a Hewlett Packard LC with a $2.1 \times 250 \mathrm{~mm}$ Dychrom Chemosorb 5-ODS-UH column using acetonitrile-water eluent. The HPLC instrument methods are described in Manual L16.1, Procedure \#ADS-2655. The methodology of sample preparation, standards, and standaxd preparation for HPLC analyses is described in SRT-ADS-96-0438. A control solution was submitted with each set of samples to verify consistent performance of the HPLC method. The control samples contained NaTPB, $1 \mathrm{~PB}$ and phenol. The results for the controls were consistently within $\pm 10 \%$ of the average.

Potassium ion concentrations were measured by flame atomic absorption using a Varian spectrAA-400 spectrometer. The samples were first digested in nitric acid by microwave heating. Each digested sample was diluted $1: 4$ (sample:suppressant) in a suppressant solution of 2000 $\mu \mathrm{g} / \mathrm{mL}$ cesium. For more concentrated samples, additional dilutions were made with $1600 \mu \mathrm{g} / \mathrm{mL}$ cesium. The method is described in Manual L16.1, Procedure \#ADS-1549.

Copper and boron concentrations were measured by Inductively Coupled Plasma Emission Spectroscopy (ICPES) using an ARL 
3580 instrument. Samples for copper were diluted $10 \mathrm{x}$ and acidified to a pH less than or equal to 2 using 5 wt $\%$ nitric acid. Spiked samples were analyzed with each sample to verify that there was no loss of copper. A $1000 \mathrm{mg} / \mathrm{L}$ copper standard purchased from High Purity, Inc. was used to prepare the spikes. Samples for boron analysis were first digested by heating in nitric acid. The methods are described in Manual L16.1, Procedure \#ADS-1509 and in Reference 20.

Silver, ruthenium, rhodium, and palladium were measured using a Fisons PQS-974 ICPMS according to the method described in Manual L16.1, Procedure \#ADS-1553. The salt solution samples were diluted by a factor of 100 with dilute nitric acid prior to analysis.

The $\mathrm{pH}$ was measured using a Radiometer autotitration system equipped with a standard size combination $\mathrm{pH}$ electrode (Orion). For alkaline samples, the system was calibrated using at two points using $\mathrm{pH} 7$ and $\mathrm{pH} 10$ standardized buffer solutions (Fisher Scientific).

Dose rates for the sample geometry used in the Co-60 gamma sources were measured with nylon film dosimeters by waste Processing Technology personnel. ${ }^{21}$

Benzene was analyzed by gas chromatography by Waste Processing Technology personnel. Samples were prepared by injecting $\sim 0.2$ $\mathrm{mL}$ of slurry into 0.1-L glass bulbs. The benzene was allowed to evaporate into the vapor space, then portions of the vapor space were injected into an HNU Model 301 gas chromatograph with 10.2 $\mathrm{eV}$ photoionization detector and $1 / 8$ inch diameter $\times 3$ ft long column packed with 3 wt 8 SP-2100 on Chromosorb 120/140 (Whatman Co.). The methods used are described in Manual L12.1, Procedure ITP-006,Rev.3 $(12 / 20 / 94)$ and Procedure ITP-OP-005, Rev. $3(12 / 20 / 94)$. 


\section{TABLE A-4. Analytical Results for Solids stability Tests}

\section{Note: All results are soluble concentrations in filtered samples.}

\begin{tabular}{|c|c|c|c|c|c|c|c|c|c|c|c|c|c|c|c|}
\hline \multirow{2}{*}{ Runt } & \multirow{2}{*}{$\begin{array}{l}5.5 \mathrm{M} \mathrm{Nat} \\
\text { Elapsed Time }\end{array}$} & \multirow{2}{*}{$\frac{3 \mathrm{MOH}}{\mathrm{K}_{+}}$} & Unirrad. & No continuo & dose rate & & & & & & & & & & \\
\hline & & & $\mathrm{pH}$ & AATPB & $3 \mathrm{~PB}$ & $2 P B$ & IPB & Phend & Ou & Ag & $\mathrm{Pu}$ & $\mathbf{F h}$ & $P d$ & 8 & Benzens \\
\hline & (days) & $(\mathrm{mg} / \mathrm{h})$ & & (mmolar) & (mmolar) & (mmolar) & (mmolar) & (mmolar) & $(m, h)$ & $(m g / L)$ & $(m, n)$ & $(m g h)$ & (mgn) & (unmolar) & (mmolar) \\
\hline & 0 & $<.09$ & - & 0.11 & 1.70 & 0.77 & 2.85 & 3.6 & 0.4 & $<.03$ & 0.8 & 0.2 & 7.4 & $\cdot$ & - \\
\hline & 7 & 32 & - & $<.03$ & $<.04$ & $<.06$ & 1.02 & 5.6 &. & $\cdot$ & $\because$ & $\cdot$ & - & - & 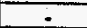 \\
\hline & 14 & 52 & - & $<.03$ & 0.05 & 0.12 & 0.30 & 7.6 & $\div$ & $\div$ & $\because$ & $\div$ & $=$ & 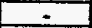 & - \\
\hline & 21 & 84 & - & $<.03$ & $<.04$ & $\leq .06$ & 0.20 & 7.7 & $\div$ & - & - & $\div$ & $=$ & - & $\div$ \\
\hline & 28 & 96 & - & - & $\cdot$ & - & $\cdot$ & - & $\cdot$ & - & - & $\therefore$ & - & - & - \\
\hline & 35 & 122 & - & - & 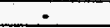 & $=$ & - & $\div$ & - & $\therefore$ & - & 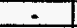 & - & - & - \\
\hline & 42 & 138 & $=$ & $\div$ & - & $=$ & - & $\div$ & - & - & - & - & $=$ & - & $=$ \\
\hline & 49 & 139 & - & - & - & $=$ & - & - & 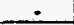 & - & - & - & - & - & $=$ \\
\hline & 56 & 225 & $\because$ & - & $=$ & $=$ & - & $\cdot$ & 5.2 & $<.03$ & 1.7 & 1.3 & 0.2 & - & - \\
\hline & & & & & & & & & & & & & & & \\
\hline Run 2 & $5.5 \mathrm{M} \mathrm{Na}+$ & $3 \mathrm{MOH}$ & $30 \mathrm{Mrad}$ & High contint & Is dose rate & & & & & & & & & & \\
\hline & Elapsed Time & $K_{+}$ & pH & NATPB & 3PB & $2 P B$ & IPB & Phond & Cu & $A g$ & Py & Ph & $P d$ & B & Benzene \\
\hline & (days) & $(m g / L)$ & & (mmolar) & (mmolar) & (mmolar) & (mmolar) & (mmolas) & $(m g / l)$ & $(\mathrm{mg} / \mathrm{L})$ & $(m g / L)$ & $(\mathrm{mg} / \mathrm{h})$ & (mg/L) & (anmoler) & (mmolar) \\
\hline & 0 & $<.005$ & 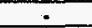 & 0.21 & 2.1 & 0.89 & 2.85 & 3.7 & 0.4 & 0.01 & 0.5 & 0.2 & 3.1 & $\cdot$ & - \\
\hline & 7 & 9.7 & $=$ & $<.03$ & 0.48 & 0.42 & 0.87 & 6.3 & - & $\cdot$ & - & $\cdot$ & 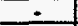 & 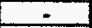 & - \\
\hline & 14 & 28 & $=$ & $<.03$ & 0.05 & 0.12 & 0.29 & 6.6 & - & - & - & $=$ & - & $=$ & $=$ \\
\hline & 21 & 53 & $=$ & $<.03$ & $<.04$ & 0.17 & 0.24 & 4.8 & $=$ & - & $=$ & - & $=$ &. & + \\
\hline & 28 & 65 & $=$ & - & - &. & $\cdot$ & 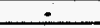 & $\cdot$ & - & - & - & - & - & - \\
\hline & 35 & 92 & $=$ & - & - & $=$ & $\therefore$ & $\dot{-}$ & - & $=$ & - & - & - & $\cdot$ & - \\
\hline & 42 & 105 & $\div$ & - & - & 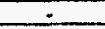 & - & - & - & $=$ & $\div$ & $\div$ & $=$ & $\div$ & $=$ \\
\hline & 49 & 141 & $\therefore$ & - & - & $=$ & - & - & - & - & $\therefore$ & - & - & - & $=$ \\
\hline & 56 & 159 & $\because$ & $\therefore$ & - & - & - & - & 2.6 & 0.1 . & 3.1 & 1.6 & 10.2 & - & - \\
\hline & & & & & & & & & & & & & & & \\
\hline Riun 3 & $5.5 \mathrm{M} \mathrm{Nat}$ & $p+110$ & Unirrad. & High contine & 13 dose rate & & & & & & & & & & \\
\hline & Elapsed Time & $K_{+}$ & pH & NATFB & 398 & $2 P B$ & 1PB & Phend & Q & $A g$ & A & Fh & Pd & $B$ & Benzene \\
\hline & (days) & $(\mathrm{mg} / \mathrm{L})$ & & (mmolar) & (mmolar) & (mmolar) & (mmolar) & (mmolar) & $(\mathrm{mg} / \mathrm{L})$ & (man) & (mg/l) & $(m, /)$ & $(\mathrm{mg} / \mathrm{L})$ & (mmolar) & (mmolar) \\
\hline & 0 & 48 & 10.55 & 0.14 & 1.10 & 3.1 & 3.3 & 2.8 & 0.1 & $<.03$ & 0.4 & 0.2 & 4.8 & $\cdot$ & - \\
\hline & 7 & 23 & 10.62 & $<.03$ & $<0.4$ & 1.9 & 4.2 & 2.0 & 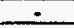 & - & $\cdot$ & - & - & $\cdot$ & $\div$ \\
\hline & 14 & 463 & 10.50 & $<.03$ & $<.04$ & 3.7 & 7.2 & 2.3 & - & $=$ & $\div$ & $\div$ & - & $\div$ & $\div$ \\
\hline & 21 & 783 & 10.50 & $<.03$ & $<.04$ & 4.1 & 0.29 & $<.1$ & - & $\cdot$ & $\therefore$ & - & - & - & - \\
\hline & $2 B$ & 812 & 10.44 & 5.03 & $<.04$ & 3.2 & - & & $\therefore$ & - & - & - & $\div$ & $=$ & - \\
\hline & 35 & 940 & 10.34 & $<.03$ & $<.04$ & 2.0 & + & & $\cdot$ & - & $=$ & $\div$ & - & - & - \\
\hline & 42 & 1094 & 10.30 & $=$ & 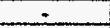 & 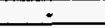 & - & & $\div$ & $=$ & $\cdot$ & - & $=$ & $=$ & $=$ \\
\hline & 49 & 1373 & 10.29 & - & $\div$ & 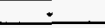 & - & & - & - & $\cdot$ & 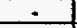 & - & - & $\cdot$ \\
\hline & 56 & 1410 & 10.19 & - & - & - & $\because$ & . & 0.4 & $<.03$ & 0.9 & 1 & 3.6 & - & - \\
\hline & & & & & & & & & & & & & & & \\
\hline $\operatorname{Bun} 4$ & $5.5 \mathrm{M} \mathrm{Nat}$ & DH 10 & 30 Mrad & No continuo & dose rate & & & & & & & & & & \\
\hline & Elapsod Time & $K_{t}$ & pH & NATPB & $3 P B$ & $2 P B$ & IPB & Phend & $a$ & $\mathrm{Ag}$ & $\mathrm{As}$ & Fh & $P d$ & B & Benzere \\
\hline & (days) & $(m g n)$ & & (mmotar) & (mmolar) & (mmolar) & (mmolar) & (mmolar) & (mg/h) & $(m g / l)$ & $(m g h)$ & $(m g h)$ & $(\mathrm{mg} / \mathrm{h})$ & (mmolar) & (mmolar) \\
\hline & 0 & 52 & 10.50 & 0.46 & 0.71 & 2.6 & 2.7 & 4.1 & 1.0 & 0.8 & 0.5 & 0.2 & 13.5 & 11.8 & $=$ \\
\hline & 7 & 155 & 10.66 & 0.30 & 0.05 & 1.9 & 3.7 & 2.2 & 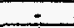 & $=$ & - & $\cdot$ & 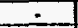 & $\cdot$ & 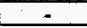 \\
\hline & 14 & 145,102 & 10.61 & $<.03$ & 0.02 & 2.2 & 6.8 & 5.6 & - & $=$ & - & - & $=$ & $=$ & $\div$ \\
\hline & 21 & 353 & 10.80 & $<.03$ & $\leq .04$ & 1.5 & 0.94 & 5.5 & - & - & - & - & $\div$ & - & - \\
\hline & 28 & 1341 & 10.80 & $<.03$ & $<.04$ & 1.4 & + & - & $\div$ & - & - & - & - & - & - \\
\hline & 35 & 2210 & 10.97 & $<.03$ & $<.04$ & 1.0 & $\div$ & - & - & $=$ & $\div$ & $\therefore$ & $\therefore$ & $\because$ & - \\
\hline & 42 & 2959 & 10.80 & $-\quad$ & - & $\cdot$ & $=$ & $\therefore$ & 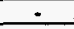 & $=$ & $\div$ & - & $=$ & - & - \\
\hline & 49 & 3373 & 11.04 & - & - & $=$ & $=$ & $\div$ & - & - & - & - & - & - & $=$ \\
\hline & 56 & 3482 & 10.98 & - & - & $=$ & 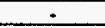 & 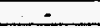 & 0.5 & $<.03$ & 1.4 & 1.2 & 1.2 & 122 & $=$ \\
\hline & & & & 1 ow contint & Tose rate & duplicate mi & oint) & & & & 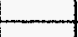 & & & & \\
\hline Run 5 & $2.8 \mathrm{M} \mathrm{Na}+$ & $\frac{p+1}{12}$ & $\frac{15 \mathrm{Mrad}}{\mathrm{pH}}$ & $\frac{\text { Low contint }}{\text { NaTPB }}$ & $\frac{\text { S dose rate }}{3 \mathrm{PPB}}$ & $\frac{\text { duplicate mi }}{2 \mathrm{~PB}}$ & IPB & Phend & $\mathrm{Cu}_{\mathrm{u}}$ & $\mathrm{Ag}$ & $F_{1}$ & Fh & Pd & 8 & Binzere \\
\hline & (days) & $\frac{n+}{(m g / h)}$ & & (mmolar) & (mmolar) & (mmolar) & (mmolar) & (mmolar) & $(\mathrm{mg} / \mathrm{L})$ & (mg/L) & $(m g / h)$ & $(m g / L)$ & $(\mathrm{mg} / \mathrm{L})$ & (mmolar) & (mmoiar) \\
\hline & 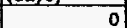 & 136 & 12.23 & 0.22 & 2.3 & 3.3 & 0.89 & 3.5 & 0.1 & 0.2 & 0.4 & 0.05 & 5.9 & 7.0 & - \\
\hline & 7 & 191 & 12.28 & 0.20 & 0.04 & 1.4 & 2.2 & 2.9 & - & - & $\cdot$ & + & - & - & - \\
\hline & 14 & 207 & 12.16 & $<.03$ & $<0.4$ & 2.0 & 2.8 & 4.3 & - & - & 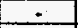 & - & $\cdot$ & - & - \\
\hline & 21 & 300 & 12.30 & $<.03$ & $<.04$ & 2.5 & 1.7 & 3.8 & - & $\therefore$ & $=$ & - & - & $=$ & - \\
\hline & 28 & 357 & 12.23 & $<.03$ & $<.04$ & 2.8 & $=$ & - & - & $=$ & $\therefore$ & $=$ & $=$ & $=$ & - \\
\hline & 35 & 367 & 12.17 & $<.03$ & $<.04$ & 2.5 & - & $=$ & $\because$ & - & $\therefore$ & - & - & - & $\div$ \\
\hline & 42 & 419 & 12.14 & $\therefore$ & - & 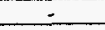 & - & $\therefore$ & $\therefore$ & - & - & 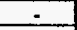 & $\div$ & $\therefore$ & 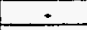 \\
\hline & 49 & 439 & 12.09 & - & $\therefore$ & $=$ & $\overline{-}$ & $=$ & $\div$ & - & - & - & $\square$ & $=$ & $=$ \\
\hline & 56 & 446 & 11.98 & - & $\because$ & $=$ & - & $=$ & 0.2 & 0.3 & 0.3 & 0.7 & 9.6 & 20.9 & - \\
\hline Run 6 & $2.8 \mathrm{MNa}+$ & $\mathrm{pH} 12$ & $15 \mathrm{Mrad}$ & Low contint & is dose tate & duplicate mi & oint) & & & & & & & & \\
\hline & Elapsed Time & $K+$ & $\mathrm{pH}$ & NaTPB & 3PB & ZPB & $1 \mathrm{~PB}$ & Phenol & cu & $\mathrm{Ag}$ & $\mathrm{Aus}$ & $F_{\text {f }}$ & $P d$ & B & Benzene \\
\hline & $\begin{array}{l}\text { (days) } \\
\end{array}$ & $(\mathrm{mg} / \mathrm{L})$ & & (mmolar) & (mmolar) & (mmolar) & (mmolar) & (mmolar) & (mg/L) & (mg/L) & (mgll) & (mg/L) & (mg/L) & (mmolar) & (mmolar) \\
\hline & 0 & 127 & 12.24 & 0.21 & 2.3 & 3.1 & 2.9 & 3.3 & 0.9 & 0.08 & 0.2 & 0.04 & 6.3 & $\div$ & - \\
\hline & 7 & 200 & 12.29 & 0.20 & 0.02 & 1.4 & 3.2 & 3.2 & - & - & $\therefore$ & $\therefore$ & $\because$ & $\div$ & - \\
\hline & 14 & 237 & 12.14 & $<.01$ & $<.04$ & 2.1 & 3.6 & 4.4 & $\cdot$ & - & - & - & - & - & - \\
\hline & 21 & 328 & 12.30 & $<.01$ & $<.04$ & 2.5 & 3.0 & 4.0 & $*$ & - & - & - & $\therefore$ & - & $=$ \\
\hline & $\angle 8$ & 349 & 12.20 & $<.01$ & $<.04$ & 2.7 & - & $\div$ & - & - & $=$ & $\cdot$ & - & - & - \\
\hline & 35 & 383 & 12.15 & $<.01$ & $<.04$ & 2.7 & $\because$ & - & - & - & - & - & $\therefore$ & - & - \\
\hline & 42 & 419 & 12.12 & - & + & 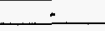 & - & - & $\therefore$ & $=$ & - & - & $\div$ & - & $\cdot$ \\
\hline & 49 & 478 & 12.07 & $\bullet$ & $\div$ & $=$ & 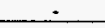 & - & $=$ & - & $=$ & - & $=$ & - & - \\
\hline & 56 & 173 & 12.07 & $=-$ & $\div$ & $\because$ & - & - & 0.2 & 0.4 & 0.2 & 0.7 & 10.0 & 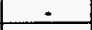 & - \\
\hline & & & & & & & & & & & & & & & \\
\hline
\end{tabular}




\section{TABLE A-4. Analytical Results for Solids stability Tests (Continued) \\ Note: All results are soluble concentrations in filtered samples.}

\begin{tabular}{|c|c|c|c|c|c|c|c|c|c|c|c|c|c|c|c|}
\hline \multirow{2}{*}{ Run 7} & \multirow{2}{*}{$\begin{array}{l}2.8 \mathrm{MNat} \\
\text { Elapsed Time }\end{array}$} & $p+12$ & \multirow{2}{*}{$\frac{15 \mathrm{Mrad}}{\mathrm{pH}}$} & Low contimu & us dose rete & $\mathrm{vO2}$ addod & & & & & & & & & \\
\hline & & & & \begin{tabular}{|l|} 
NaIPB \\
\end{tabular} & $3 P 8$ & $2 P B$ & IPB & Phenol & as & $\mathrm{Ag}_{\mathrm{g}}$ & A & In & Pd & B & Eenzene \\
\hline & & (mg/L) & & (mmolar) & (mmolar) & (mmolar) & (mmolar) & (mmolar) & (mg/L) & $(m g h)$ & $(m g h)$ & $(m g / h)$ & $(\mathrm{mgn})$ & (mmolar) & (mmoler) \\
\hline & 0 & 118 & 12.09 & 0.20 & 2.4 & 2.8 & 2.8 & 3.5 & 0.1 & 0.2 & 0.2 & 0.05 & 6.0 & & \\
\hline & 7 & 199 & 12.03 & 0.18 & $<.04$ & 1.5 & 3.5 & 3.4 & - & - & $\because$ & - & - & & - \\
\hline & 14 & 253 & 12.04 & $<.03$ & $<.04$ & 1.6 & 3.8 & 4.2 & - & $\cdot$ & $\because$ & $\cdot$ & - & - & $=$ \\
\hline & 21 & 310 & 12.10 & $<.03$ & 0.07 & 2.1 & $\cdot$ & $\cdot$ & - & - & $\therefore$ & - & - & - & $\div$ \\
\hline & 28 & 358 & 11.99 & $<.03$ & $<.04$ & 2.9 & $=$ & - & - & - & $=-$ & - & - & - & $\because$ \\
\hline & 35 & 406 & 11.96 & $<.03$ & $<.04$ & 2.9 & - & $\cdot$ & $\div$ & $\because$ &.- & - &. & - & \\
\hline & 42 & 467 & 11.93 & - & - & - & - & - &. & - & - & - & - & - & 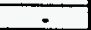 \\
\hline & 49 & & 11.97 & $\div$ & - & $\div$ & $\div$ & $\div$ & $\cdot$ & - & - & 7 & - & - & 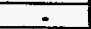 \\
\hline & 56 & 623 & 14.85 & - & $\because$ & $\square$ & $\therefore$ & $\therefore$ & 0.1 & 0.2 & 0.1 & 0.5 & 6.9 & - & $=$ \\
\hline Run 8 & $2.8 \mathrm{MNat}$ & pH 12 & 200 Mrad & & us dose rasp & y high pre-do & & & & & & & & & \\
\hline & Elapsed Tine & $K_{+}$ & $\mathrm{pH}$ & NaTPB & 398 & 2PB & $1 \mathrm{~PB}$ & Phenol & as & $\mathrm{Ag}$ & A & Fh & $\mathrm{Pd}$ & \begin{tabular}{|l} 
B \\
\end{tabular} & Benzene \\
\hline & $($ days $)$ & $\operatorname{lmg} / 2$ & & (mmolar) & (mmolar) & (mmolar) & (mmolar) & Immolar) & (mg/h) & (mgh) & (mg/L) & (mgh) & (mg/L) & (mmolar) & (mmolar) \\
\hline & ( & 409 & 12.00 & 0.73 & 20 & 1.09 & 5.0 & 4.1 & 1.2 & 0.3 & 0.2 & 0.2 & 9.8 & - & \\
\hline & 7 & 329 & 12.00 & 0.68 & 0.64 & 0.71 & 3.4 & 4.7 & - & $\cdot$ & 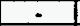 & - & - & - & \\
\hline & 14 & 322 & 11.73 & $<0.3$ & 0.24 & 0.46 & 5.8 & 8.5 & - & - & - & $\cdot$ & - & - & \\
\hline & 21 & 342 & 11.80 & $\leq .03$ & 0.14 & 0.24 & 3.5 & 8.2 & $\cdot$ & $\cdot$ & $\cdot$ & - & $\because$ & - & \\
\hline & 28 & 338 & 11.62 & $\ldots$ & - & - & - & & - & $=$ & - & $\div$ & $=$ & - & \\
\hline & 35 & 444 & 11.42 & $\therefore$ & - & $\therefore$ & - & - & - & $\therefore$ & - & $\therefore$ & + & 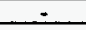 & \\
\hline & 42 & 401 & 11.27 & - & - & - & $=$ & - & 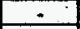 & $\therefore$ & $\therefore$ & - & - & - & \\
\hline & 49 & 404 & 11.13 & $\cdot$ & - & $\div$ & $\div$ & $\therefore$ & $\because$ & $\cdot$ & $\div$ & $\div$ & $\div$ & $\because$ & 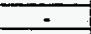 \\
\hline & 56 & 406 & 10.88 & $=$ & - & $\therefore$ & $\cdot$ & - & 2.6 & 0.3 & 0.3 & 0.8 & 8.9 & - & \\
\hline & & & & & & & & & & & & & & & \\
\hline $\operatorname{Rin} \theta$ & $0.65 \mathrm{M} \mathrm{Nat}$ & $0.50 \mathrm{MOH}$ & Unirrad. & High continy & pus dose rate & & & & & & & & & & \\
\hline & Elapsed Tine & $\mathbf{K}_{+}$ & $\mathrm{pH}$ & NaTPB & $3 P 8$ & $2 P B$ & IPB & Phenol & a & $\mathrm{Ag}$ & A & Fh & $F d$ & B & Benzene \\
\hline & (days) & $(m g / h)$ & & (mmolar) & (mmolar) & (mmolar) & (mmolar) & (mmolar) & $(\mathrm{mg} / \mathrm{L})$ & $(\mathrm{mgn})$ & $(\mathrm{mgh})$ & (mg/L) & $(\mathrm{mg} / \mathrm{L})$ & (mmolar) & (mmolar) \\
\hline & 0 & 0.8 & $\vdots$ & 1.2 & 0.22 & 1.62 & 3.6 & 3.9 & 0.1 & $<.03$ & 0.1 & 0.01 & 3.3 & - & \\
\hline & 7 & 73 & - & $<.03$ & $<.04$ & 0.63 & 3.1 & 7.0 & 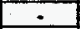 &. & 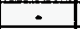 & - & - & - & \\
\hline & 14 & 70 & . & 0.006 & $<0.4$ & 0.97 & 2.8 & 10.2 & $=$ & $\cdot$ &. & $\cdot$ & - & 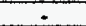 & \\
\hline & 21 & 128 & - & $<.03$ & 0.04 & 0.46 & 1.4 & 10.6 & $\cdot$ & - & - & - & $=$ & $=$ & \\
\hline & 28 & 158 & $\div$ & . & $\div$ & $=$ & - & - & - & 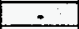 & $\therefore$ & $\because$ & $=$ & $\because$ & \\
\hline & 35 & 209 & - & - & $\div$ & - & $\cdot$ & $\cdot$ & . & $\cdot$ & - & $\bullet$ & - & - & \\
\hline & 42 & 211 & $\div$ & - & $\because$ & $\cdot$ & $\cdot$ & $\div$ & $\ldots$ & - & $\cdot$ & $\cdot$ & $=$ & 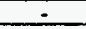 & \\
\hline & 49 & 203 & - & $=$ & $\therefore$ & - & - & $\div$ & $\div$ & 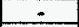 & - & & $=$ & $\div$ & $=$ \\
\hline & & 190 & - & - & - & - & - & $\div$ & 0.4 & $<.03$ & 0.3 & 0.2 & 5.3 & - & \\
\hline & & & & & & & & & & & & & & & \\
\hline Run 10 & $0.65 \mathrm{M} \mathrm{Na}$ & $0.50 \mathrm{M} \mathrm{OH}$ & 30 Mrad & Na continetor & $s$ dose rate. & & & & & & & & & & \\
\hline & Elapised Tine & $K_{+}$ & PH & NaIPB & $3 P 8$ & $2 P B$ & IPB & Phenol & Cu & $\mathrm{Ag}$ & Pu & Ph & Ad & B & Benzene \\
\hline & (days) & $(\mathrm{mg} / \mathrm{L})$ & & (mmolar) & (mmolar) & (mmolar) & (mmolar) & (mmolar) & $(\mathrm{mg} / \mathrm{L})$ & (mg/L) & $(\mathrm{mg} / \mathrm{L})$ & (mg/L) & (mg/L) & (mmolar) & (mmolar) \\
\hline & 0 & 1.1 & - & 0.97 & 2.7 & 0.95 & 2.6 & 4.2 & 0.2 & 1.0 & 0.3 & 0.01 & 5.8 & 14.2 & \\
\hline & 7 & 3.3 & - & 0.59 & 2.5 & 1.13 & 2.5 & 3.9 & - & - & - & - & $=$ & - & $\therefore$ \\
\hline & 14 & 5.9 & - & 0.18 & 1.8 & 1.52 & 3.0 & 5.2 & - & - & - & $\cdot$ & - & - & 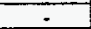 \\
\hline & 21 & 22 & - & 0.10 & 1.2 & 1.39 & 3.3 & 5.7 & - & - & 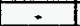 & - & - & - & \\
\hline & 28 & 34 & $\cdot$ & $<.03$ & 0.79 & 1.27 & 5 & - & $\cdot$ & 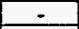 & - & $\div$ & - & - & \\
\hline & 35 & 73 & - & $\cdot$ & $\cdot$ & . & - & - & $\therefore$ & $\ldots$ & $\cdot$ & 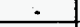 & - & - & - \\
\hline & 42 & 47 & - & - & - & - & - & - & $\therefore$ & $=$ & $=$ & $\therefore$ & - & - & + \\
\hline & & 52 & - & $=$ & - & 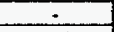 & - & - & & $\because$ & & & & & \\
\hline & 56 & 58 & 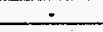 & $\therefore$ & - & - & - & $\div$ & 0.2 & $<.03$ & 0.7 & 0.3 & 5.3 & 19.0 & - \\
\hline & & & & No continut & Chosota & & & & & & & & & & \\
\hline Run 11 & $0.1 \mathrm{MNat}$ & $\frac{\mathrm{pH}+10}{\mathrm{Kt}}$ & Unirad. & No continuou & $\frac{3 \text { dose rate. }}{3 \mathrm{PBg}^{2}}$ & $2 P 8$ & $\mathbf{P B}$ & Phend & $C_{u}$ & $\mathrm{Ag}$ & Fy & Fi & लि & 8 & Benzene \\
\hline & $\begin{array}{l}\text { (days) } \\
\end{array}$ & (mg/L) & & (mmolar) & (mmolar) & (mmolar) & (mimolar) & (mmolar) & (mg/L) & {$[\operatorname{mg} h)$} & (mg/L) & (mg/L) & (Img/u) & \begin{tabular}{|l} 
(ntmolar) \\
\end{tabular} & (mmolat) \\
\hline & 0 & 1.5 & 10.07 & 0.90 & 0.79 & 1.26 & 2.3 & 2.8 & 0.1 & $<.001$ & $<.1$ & 0.007 & 0.008 & 6.6 & \\
\hline & 7 & 168 & 10. & $<.03$ & $<.04$ & 0.63 & 5.0 & 6.3 & - & - & - & 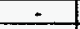 & $\cdot$ & - & \\
\hline & 14 & 250 & 10.24 & 0.012 & $<.04$ & 0.31 & 4.2 & 7.5 & $\div$ &. & $\div$ & $=$ & - & - & - \\
\hline & 21 & 447 & 10. & $<.03$ & $<.04$ & 0.38 & 3.9 & 8.0 & - & $\therefore$ & - & - & - & - & $\div$ \\
\hline & 28 & 556 & 10.36 & & - & - & $\therefore$ & - & - & - & - & - & - & - & \\
\hline & 35 & 893 & 10.28 & $\because$ & - & - & $\because$ & 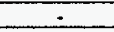 & $\div$ & $\cdot$ & 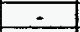 & - & - & - & \\
\hline & 42 & 894 & 10.28 & $\therefore$ & - & - & $\div$ & 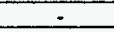 & $\because$ & - & $\cdot$ & $\div$ & - & $\div$ & $\therefore$ \\
\hline & 49 & 1247 & 10.36 & $\cdot$ & - & - & $\because$ & - & 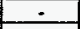 & - & $\therefore$ & $\therefore$ & - & - & \\
\hline & 56 & 1446 & 10.20 & - & - & - & - & - & 0.2 & $<.03$ & $<.1$ & $<.05$ & 0.3 & 53.4 & \\
\hline & (1) & DH 10 & Unirad & No continuto & s dose rate & N2 fiush & & & 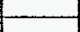 & & & & & & \\
\hline Run 12 & \begin{tabular}{|l}
0.1 M Nat \\
Elapsed Time
\end{tabular} & $\frac{\mathrm{ph}}{\mathrm{K}_{4}}$ & pH & No colps & $\frac{5805 \theta}{3 P B}$ & $\frac{N<105}{2 P B}$ & 198 & Phenol & $\mathrm{Cu}$ & $A g$ & Fus & Fo & $P d$ & $B$ & Benzens \\
\hline & $\begin{array}{l}\text { (days) } \\
\end{array}$ & $(\mathrm{mg} / \mathrm{l})$ & & (mmolar) & (mmolar) & (mmolar) & (mmolar) & (mmolar) & $(\mathrm{mg} / \mathrm{L})$ & $(m g / h)$ & (mg/) & (mg/L) & $(\mathrm{mg} / \mathrm{L})$ & (mmolar) & (mmolar) \\
\hline & 0 & 1.5 & 10.22 & 0.90 & 1.9 & 1.21 & 2.3 & 2.9 & 0.1 & $<.03$ & $<.02$ & 0.007 & 0.12 & 6.5 & \\
\hline & 7 & 140 & 10. & & 0.02 & & 5.5 & 5.6 & & $\cdots$ & - & - & $\cdot$ & $\cdot$ & $=$ \\
\hline & 14 & 251,292 & 10 & 0.006 & $<0.4$ & 0.47 & 4.7 & 6.7 & $\therefore$ & $\therefore$ & 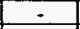 & - & - & - & $\therefore$ \\
\hline & 21 & 431 & 10.60 & $<.03$ & 0.01 & 0.42 & 4.3 & 7.4 & - & - & - & - & $\div$ & - & $\div$ \\
\hline & 28 & 515 & 10.51 & & & & & - & - & 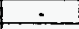 & - & $\cdot$ & $\cdot$ & - & \\
\hline & 35 & 690 & 10.45 & - & $\cdot$ &. & $\therefore$ & $\therefore$ & $\div$ & - & $\cdot$ & - & - & - & \\
\hline & 42 & 712 & 10.44 & $\because$ & $\therefore$ & & & $\div$ & - & $\div$ & - & $\therefore$ & $\therefore$ & - & - \\
\hline & 49 & 861 & 10.08 & - & $\therefore$ & - & $\div$ & $\cdot$ & $\therefore$ & $<03$ & $<2$ & $<007$ & 003 & -1 & \\
\hline & 56 & 989 & 10.46 & - & - & - & & & 0.1 & & & & 0.03 & & \\
\hline
\end{tabular}




\section{TABLE A-4. Analytical Results for Solids stability Tests (Continued) \\ Note: All results are soluble concentrations in filtered samples.}

\begin{tabular}{|c|c|c|c|c|c|c|c|c|c|c|c|c|c|c|c|}
\hline $\operatorname{sen} 13$ & $0.1 \mathrm{MNa}$ & pH 10 & $30 \mathrm{Mrad}$ & High contine & ous dose rate & & & & & & & & & & \\
\hline & Elapsed Time & $K_{t}$ & pth & NGIPB & $3 P B$ & $2 P B$ & IPB & Phend & an & $\mathrm{Ag}$ & Pu & An & $\mathrm{Pd}$ & $B$ & Benzene \\
\hline & (days) & $(\mathrm{mg} / \mathrm{L})$ & & (mmolar) & & (mmolar) & (mmolar) & (mmolar) & $(\mathrm{mgn})$ & $(m g /)$ & (magl) & (mg/L) & (mg/L) & (mmolar) & (mmolan) \\
\hline & & 2 & 10.10 & 0.81 & 2.2 & 0.64 & 2.19 & 3.1 & 0.5 & 0.01 & 0.02 & 0.01 & 5.7 & & \\
\hline & 7 & 67 & 10.22 & $<.03$ & 0.39 & $<.06$ & 1.26 & 6.7 & $\therefore$ & $\therefore$ & $\ldots$ & & & - & $=$ \\
\hline & 14 & 33 & 9.99 & 0.05 & 0.01 & $<.06$ & $<.08$ & 9.5 & $=$ & $\div$ & - & - & $=$ & $=$ & - \\
\hline & 21 & 70 & 10.20 & $<.03$ & 0.05 & $<.06$ & $<.08$ & 7.8 & $\therefore$ & - & - & $\div$ & - & $\therefore$ & $\dot{-}$ \\
\hline & 28 & 79 & 10.14 & $\cdots$ & - & - & - & $\therefore$ & $\div$ & - & $\therefore$ & $\because$ & - & $\div$ & $\cdot$ \\
\hline & 35 & 106 & 10.03 & - & - & 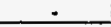 & - & - & - & $=$ & - & 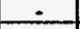 & - & - & - \\
\hline & 42 & 110 & 10.00 & - & $=$ & - & - & $\therefore$ & $二$ & $\therefore$ & $\cdot$ & - & $\div$ & 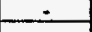 & $\therefore$ \\
\hline & 49 & 134 & 10.10 & $=$ & - & - & - & $\therefore$ & - & & & & & - & - \\
\hline & 56 & 136 & 9.80 & - & - & $\div$ & $\therefore-$ & - & 4.6. & 0.2 & 0.2 & 0.3 & 7.5 & - & - \\
\hline & & & & & rie dos & 10 solide & 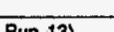 & & & & & & & & \\
\hline Run 14 & $0.1 \mathrm{MNat}$ & $\mathrm{pH}+10$ & $\frac{30 \mathrm{Mrad}}{\mathrm{pty}}$ & High continu & $\frac{\text { ous dose rate, }}{3 P 8}$ & $\frac{1 / 2 \text { solids (V) }}{208}$ & $\frac{\text { Run } 13)}{198}$ & Phend & $a_{i}$ & $A g$ & Fu & Ph & $P d$ & $\bar{B}$ & Benzene \\
\hline & (days) & $(\mathrm{mg} / \mathrm{L})$ & & (mmolar) & (mmolar) & (mmolar) & (mmolar) & Immolar) & (mg/) & $(\mathrm{mg} / \mathrm{L})$ & $(\mathrm{mgh})$ & $(m g / t)$ & (mg/L) & (mmolan) & $\begin{array}{l}\text { Benzeeno } \\
\text { (mmoliar) }\end{array}$ \\
\hline & & 1.7 & 10.06 & 0.96 & 1.90 & 0.64 & 2.16 & 3.2 & 0.5 & $<.08$ & 0.04 & 0.02 & 3.8 & & \\
\hline & 7 & 44 & 10.19 & $<.03$ & 0.39 & $<.06$ & 1.30 & 6.5 & $\cdot$ &. & - & & & $\therefore$ & \pm \\
\hline & 14 & 33 & 9.94 & 0.08 & $<.04$ & $<.06$ & $<.08$ & 7.9 & $\therefore$ & - & - & $\therefore$ & $\therefore$ & 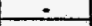 & - \\
\hline & 21 & 48 & 10.08 & 0.10 & $<.04$ & $<.06$ & $<.08$ & 6.0 & $\therefore$ & - & - & - & - &. & - \\
\hline & 28 & 63 & 10.04 & 0.04 & $<.04$ & 0.06 & & - & $\cdot$ & - & - & - & $\div$ & - & - \\
\hline 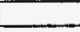 & 35 & 72 & 8.82 & $\therefore$ & $=$ & - & - & $\div$ & - & - & $=$ & $=$ & $\cdot$ & $\cdot$ & - \\
\hline & 42 & 23 & 8.69 & - & $\cdot$ & - & $\therefore$ & - & $\therefore$ & - & - & $\div$ & - & $=$ & - \\
\hline & 49 & 125 & 9.70 & $\cdot$ & - & $\therefore$ & - & - & $\therefore$ & $\cdot$ & $\rightarrow$ & - & & - & \\
\hline & 56 & 120 & 9.67 & - & - & $\div$ & $\therefore$ & $=$ & 5.1 & 0.6 & 0.1 & 0.3 & 8.5 & - & $=$ \\
\hline Bun 15 & $28 \mathrm{MNat}$ & of 10 ( $\mathrm{CO} 2$ & $15 \mathrm{Mrad}$ & Law continut & us dose rate & & & & & & & & & $\cdots$ & \\
\hline mon & Elapsed Time & $\frac{K_{+}}{K_{+}}$ & pH & NaTPB & 3PB & $2 P B$ & IPB & Phend & $a_{1}$ & Ag & Au & क & $P d$ & B & Banzene \\
\hline & (days) & $(m g n)$ & & (mmolar) & (mmolar) & (mmolar) & (mmolar) & (mmolar) & (mgh) & $(\mathrm{mg} /)$ & (mg/h) & (mg/L) & (mgR) & (mmolar) & (mmolar) \\
\hline & 0 & $<1$ & 10.2 & 2.1 & 1.72 & 5.3 & 1.48 & 0.5 & , & $<.05$ & 0.03 & 0.01 & 3.8 & & . \\
\hline & 7 & 209 & $\cdot$ & $<.03$ & $<.05$ & 0.32 & 7.5 & 3.2 & $\div$ & - & $\cdot$ & $\therefore$ & - & $=$ & $=$ \\
\hline & 14 & 250 & - & $\begin{array}{r}<.03 \\
\end{array}$ & $<.05$ & 0.41 & 3.8 & 3.7 & - & - & $\therefore$ & - & - & - & \\
\hline & 21 & 338 & - & $<.03$ & $<.05$ & 0.55 & 3.5 & 4.8 & - & $\div$ & $\cdot$ & $\therefore$ & - & - & -5 \\
\hline & 28 & 457 & - & $<.03$ & $<.05$ & 0.57 & 3.0 & 5.8 & $\therefore$ & $\therefore$ & $\div$ & - & $=$ & - & - \\
\hline & 35 & 727 & - & $<.03$ & $<.05$ & 0.41 & 2.6 & 5.8 & & & & & & - & \\
\hline & 42. & 617 & 10.12 & $<.03$ & $<.05$ & 0.26 & 2.7 & 5.7 & $\therefore$ & $<.02$ & 0.43 & 0.81 & 1.81 & - & - \\
\hline Run 16 & $2.8 \mathrm{M} \mathrm{Na}$ & pt $10(\mathrm{CO} 2)$ & 15 Mrad & Low conlinu & us dose rate & & & & - & 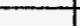 & & & & & \\
\hline & Elapsed Time & $\mathrm{K}+$ & $\mathrm{pH}$ & NaTPB & $3 P B$ & 298 & $1 P 3$ & Phend & $a_{u}$ & $\mathrm{Ag}$ & Pu & $P$ h & $P d$ & 8 & Benzene \\
\hline & \begin{tabular}{|l|l|} 
(days) \\
\end{tabular} & $(m g \Omega)$ & & Smmolar) & (mmolar) & (mmolar) & (mmolar) & (mmolar) & $(m g n)$ & $(\mathrm{mg} / \mathrm{L})$ & $\operatorname{lngh}$ & (mg/h) & (mg/h) & (mmolar) & (mmolar) \\
\hline & 0 & $<1$ & 9.94 & 2.2 & 1.81 & 5.5 & 1.15 & 0.6 & .1 & $<.05$ & 0.02 & 0.01 & 3.4 & & \\
\hline & 7 & 235 & 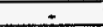 & $<.03$ & $<.05$ & 0.18 & 5.5 & 2.9 & - & - & $\div$ & $\cdot$ & $\div$ & - &. \\
\hline & 14 & 270 & - & $<.03$ & $<.05$ & 0.21 & 2.7 & 4.6 & - & $\therefore$ & $\therefore$ & - & $\therefore$ & 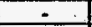 & $-\sigma_{-1}$ \\
\hline & 21 & 366 &. & $<<.03$ & $<.05$ & 0.22 & 1.76 & 5.6 & $\because$ & $\because$ & $=$ & - & $\therefore$ & & \\
\hline & 28 & 498 & $\div$ & $<.03$ & $<.05$ & 0.19 & 1.68 & 7.5 & - & - & $\because$ & $=$ & - & & \\
\hline & 35 & 627. & & $<.03$ & $<.05$ & 0.18 & 1.72 & 6.3 & & & & & 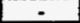 & - & \\
\hline & 42 & 709 & 9.95 & $<.03$ & $<.05$ & 0.07 & 1.23 & 5.7 & - & $<.02$ & 0.52 & 0.85 & 1.66 & - & - \\
\hline & & & & Wh & cotion & & & & & & & $\ldots$ & $m+2+3$ & $-m+2+$ & $\ldots$ \\
\hline Run 17 & $2.8 \mathrm{M} \mathrm{Na}+$ & $\mathrm{pH} 10(\mathrm{CO} 2)$ & 15 Mrad & N2 inerted, & $\frac{10 \text { continuous }}{3 P 8}$ & $\frac{\text { ose rate. }}{2 p \theta}$ & 108 & Phend & $\mathrm{Cu}$ & & & Ph & $P d$ & $\bar{B}$ & \\
\hline & $\begin{array}{l}\text { Eapsed Iime } \\
\text { (doays) }\end{array}$ & $\frac{\mathrm{K}+}{(\mathrm{mg} / \mathrm{L})}$ & PA & (mmolar) & (mmolar) & (mmolar) & (mmolat) & (mmolar) & $(m g / \Omega)$ & $\frac{m g}{(m g)}$ & (mg/L) & $\frac{m}{(m g / t)}$ & $(\mathrm{mg} / \mathrm{L})$ & $\frac{B}{\text { (mmolar) }}$ & \begin{tabular}{|l} 
Benzenene \\
(mmialar)
\end{tabular} \\
\hline & 0 & $<1$ & 10.30 & 2.1 & 1.72 & 5.5 & 1.74 & 0.6 & - & $<.05$ & 0.03 & 0.01 & 4.1 &. & - \\
\hline & 7 & 252 & $\cdot$ & $<.03$ & 0.066 & 0.76 & 10.0 & 2.5 & & $\cdot$ & . & - $\div$ & & - & - \\
\hline & 14 & 345 & - & $<.03$ & $<.05$ & 0.79 & 10.7 & 2.5 & - & . & $=$ & - & $\therefore$ & - & 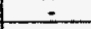 \\
\hline & 21 & 494 & $\div$ & $<.03$ & $<.05$ & 0.76 & 10.2 & 3.5 & $\therefore$ & $\therefore$ & - & - & $=$ & $\dot{-}$ & $\dot{-}$ \\
\hline & 28 & 653 & $\therefore$ & $<.03$ & $<.05$ & 0.68 & 11.6 & 5.0 & - & $\therefore$ & - & $\because$ & $\div$ & - & - \\
\hline & 35 & 783 & 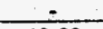 & $\begin{array}{r}<.03 \\
\end{array}$ & $<.05$ & 0.66 & 11.0 & 4.5 & $\therefore$ & & & & & $=$ & $=$ \\
\hline & 42 & 910 & 10.62 & $<.03$ & $\leq .05$ & 0.58 & 10.2 & 5.3 & - & $<, 02$ & 0.59 & 0.76 & 0.2 & $\because$ & $=$ \\
\hline Pun 18 & $2.8 \mathrm{M} \mathrm{Na}+$ & $\mathrm{pH} 10\left(\mathrm{CO}^{2}\right)$ & 15 Mrad & 2.5 wt \% so & ids, high contil & yous dose ra & & & & & & & & & \\
\hline & Elapsed Tine & $\frac{K_{+}}{}$ & $\mathrm{PH}$ & NATPB & $3 P B$ & 2PB & $1 P 8$ & Phend & $\mathrm{Cu}$ & $\mathrm{Ag}$ & Fu & Ph & $P d$ & 8 & Benzenes \\
\hline & (days) & (mgll) & & (mmolar) & (mmolar) & (mmolar) & (mmolar) & (mmolar) & $(m g / 4)$ & $(m g / L)$ & (mg/L) & $(\mathrm{mg} / \mathrm{l})$ & $(\mathrm{mg} / \mathrm{L})$ & (mmolar) & (mmolar) \\
\hline & 0 & $<1$ & 10.30 & 2.0 & 1.63 & 5.1 & 1.66 & 0.6 & & $<.05$ & 0.02 & 0.01 & 3.8 & & \\
\hline & 7 & 137 & -5 & $<.03$ & $<.05$ & 0.71 & 5.6 & 1.3 & $=$ & - & - & - & $\therefore$ & $\cdot$ & $\because$ \\
\hline & 14 & 256 & - & $<.03$ & 5.05 & 1.54 & 4.8 & $0.7>$ & $\therefore$ & - & - & $\therefore$ & -1 & & $\therefore$ \\
\hline & 21 & 378 & $=$ & $<.03$ & $<.05$ & 1.64 & 3.7 & 0.7 & - & $\cdot$ & $\therefore$ & $\therefore$ & - & & $=$ \\
\hline & 28 & 502 & - & $<.03$ & $<.05$ & 1.8 & 3.8 & 0.6 & $\therefore$ & - & $\therefore$ & - & - & $=$ & - \\
\hline & 35 & 650 & - & $<.03$ & $<.05$ & 1.69 & 4.5 & 0.6 & ت & 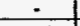 & & & & & - \\
\hline & 42 & 949 & 10.05 & $<<.03$ & $<.05$ & 1.12 & 4.2 & 2.0 & * & $>19$ & 0.46 & 0.77 & 6.6 & $\div$ & - \\
\hline Run 19 & $5.5 \mathrm{M} \mathrm{Na}+$ & $\mathrm{pH} 10(5.0 \mathrm{n}$ & $4 \mathrm{HNO} 3 \mathrm{U}$ & nimad. High & & & & & & Rate $m$ & & & & & \\
\hline , & Elapsed Tine & $\frac{10}{K+}$ & $\mathrm{pH}$ & NaTPB & $3 P B$ & 298 & $1 \mathrm{PQ}$ & Ftrend & $\mathrm{Cu}_{u}$ & $\mathrm{Ag}$ & Pas & $P f_{1}$ & $P d$ & $B$ & Benzene \\
\hline & $\frac{\mid l d a y s)}{\text { (da) }}$ & (mg/h) & & (mmolar) & (mmolar) & (mmolar) & (mmolar) & (mmolas) & $(\mathrm{mg} / \mathrm{L})$ & (mg/Ll & (mg/L) & $(\mathrm{mg} / \mathrm{ll})$ & (mg/L) & (mmolar) & (mmolar) \\
\hline & 0 & 2 & 10.60 & $<.03$ & 1.12 & 3.1 & 2.3 & 1.6 & - & $<.05$ & 0.38 & 0.13 & 3.0 & 4.0 & 1.5 \\
\hline & 5 & 154 & & $<.03$ & $\leq .05$ & 2.3 & 5.5 & 2.4 & $=$ & $=$ & - & - & - & $=$ & - \\
\hline & 12 & 305 & $=$ & $<.03$ & $<.05$ & 2.4 & 5.9 & 1.1 & - & $\therefore-$ &. & $\therefore$ & - & - & $\therefore$ \\
\hline & 19 & 503 & - & $<.03$ & $<.05$ & 3.2 & 7.0 & 1.c & 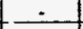 & & & & & & \\
\hline & 27 & c35 & - & $<.03$ & $\leq .05$ & 3.6 & 8. & 0.8 & & $<.05$ & 0.83 & 0.87 & 1.8 & 23.3 & \\
\hline & 34 & 808 & - & $<.03$ & $<.05$ & 2.6 & 10.4 & 0.9 & & & & & & - & 0.7 \\
\hline & 41 & 865 & 9.89 & $<.03$ & $<.05$ & 1.5 & 10.8 & 1.8 & 0.79 & $<.05$ & 0.76 & 0.87 & 2.7 & - & \\
\hline & & & & & & & & & & & & & & & \\
\hline
\end{tabular}




\section{TABLE A-4. Analytical Results for solids stability Tests (Continued)}

Note: All results are soluble concentrations in filtered samples.

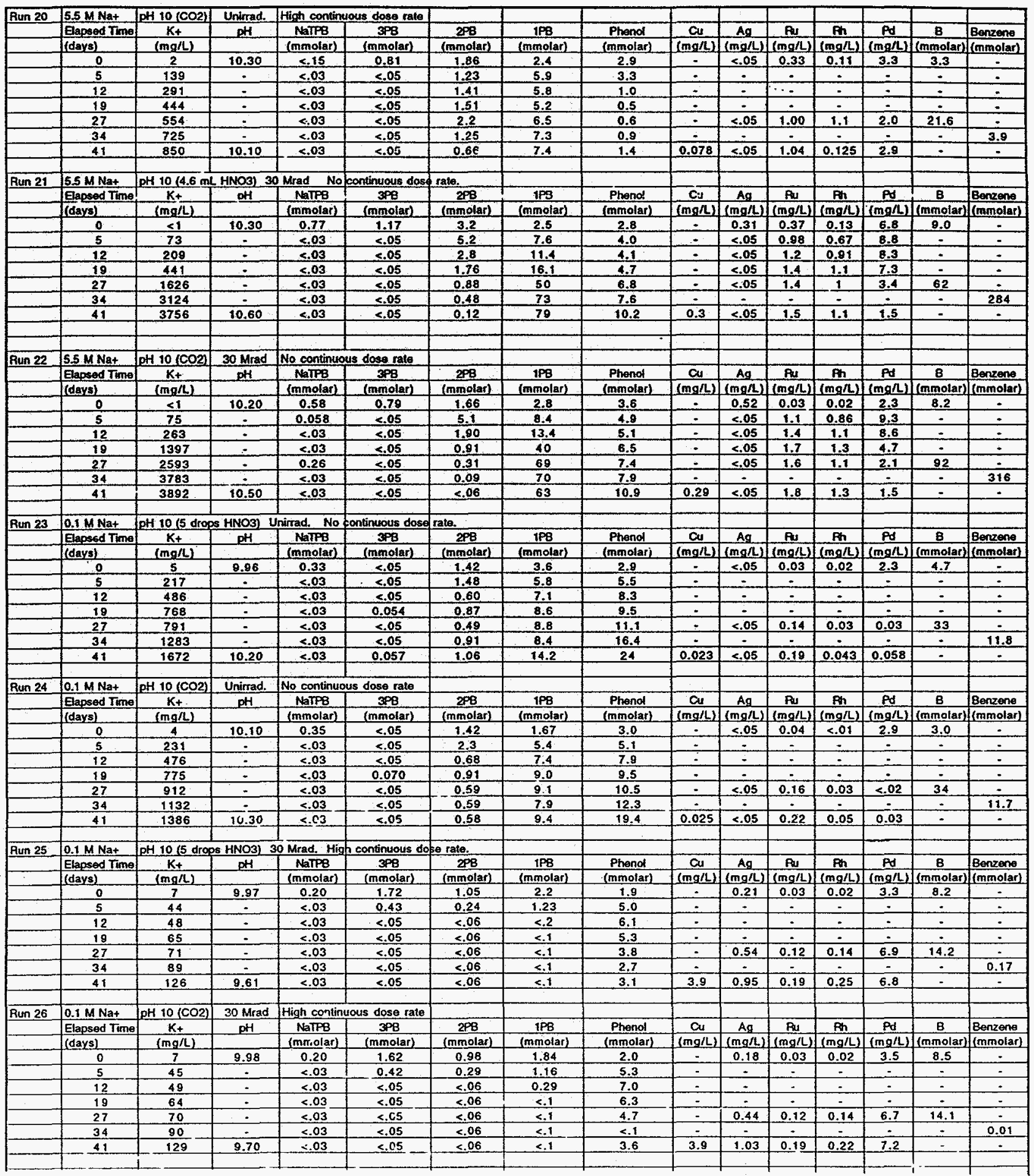


TABLE A-4. Analytical Results for solids stability rests (Continued)

Note: AII results are soluble concentrations in filtered samples.

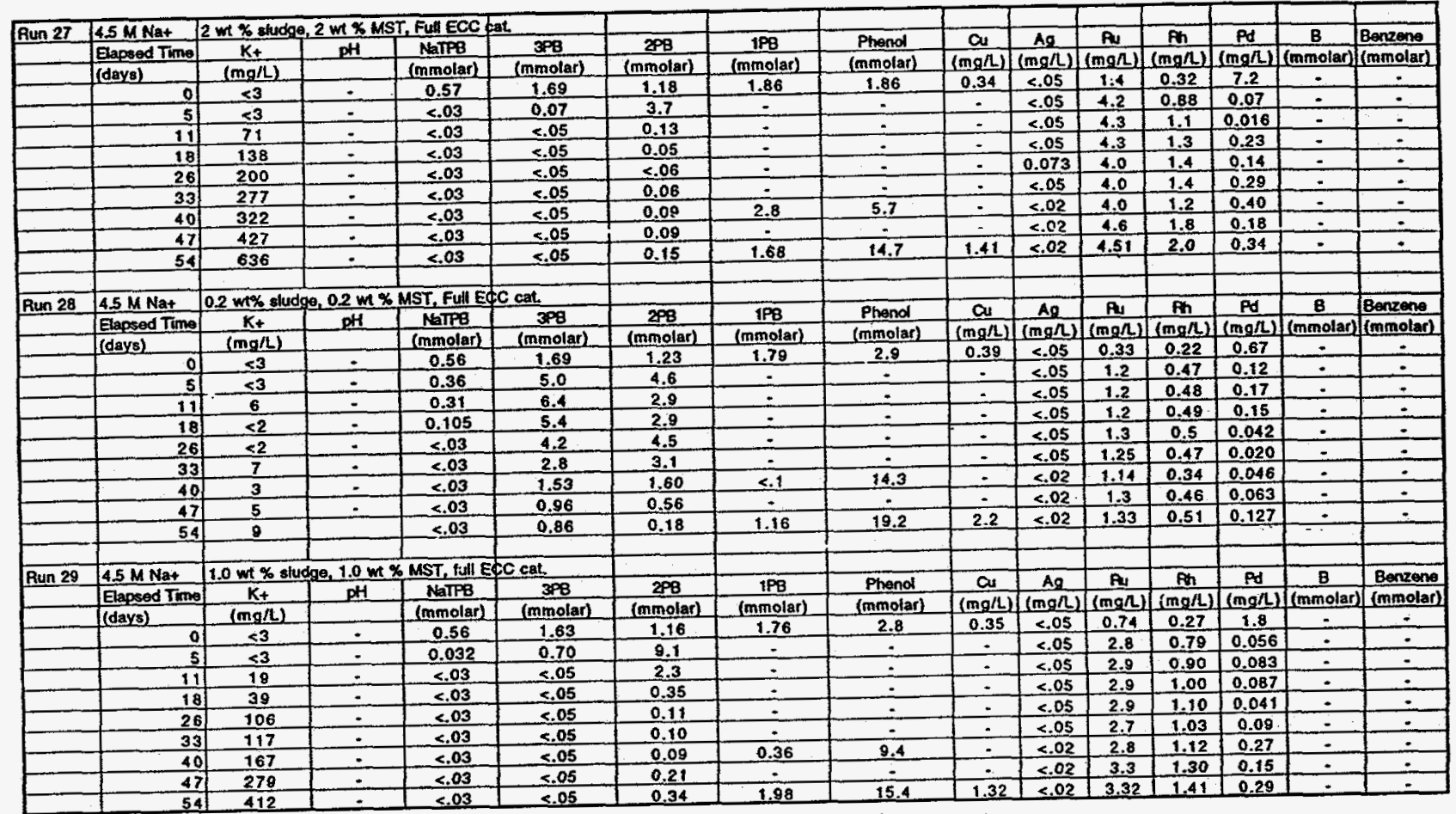

TABLE A-5. Comparison of Initial and Repeat Analyses of Samples showing High $\mathrm{K}^{+}$and NaTPB

Sample

Run 4

Day 0

Day 0 (repeat) *

Run 8

Run 12

Day 0

Day 0

Day 0

Day 0 (repeat)*
Concentration

$\underline{\mathrm{K}}^{+}$

NaTPB

52

45

409

404

1.5

5

315

$<10$

$<10$ $(\mathrm{mg} / \mathrm{L})$

3PB 2 PB

173

201

475

495

521

452

505
220

252

*The Day 0 (initial) filtrate samples were re-analyzed after 6 weeks storage at room temperature. 


\section{APPENDIX B \\ statistical Analysis}

\section{Experimental Design}

A designed experimental plan was developed to study the influence of four factors $\mathrm{Na}^{+}$molar concentration, $\mathrm{pH}$, pre-irradiation in Mrad, and dose rate in $\mathrm{rad} / \mathrm{hr}$ ) on the stability of the solids in solutions typical of those processed at ITP. This designed experiment consisted of ten experiments. Subsequently, additional experimental trials were conducted. The results from all of these experiments are presented in Table 1. Note that $\mathrm{pH}$ column is expressed as two additional columns: $\mathrm{OH}^{-}$molar concentration and its reciprocal.

\section{Table B-1: Experimental Design and Results}

\begin{tabular}{|c|c|c|c|c|c|c|c|c|}
\hline Notes & $\begin{array}{c}\text { Flask } \\
\#\end{array}$ & $\underset{\text { (molar) }}{\mathrm{Na}^{+}}$ & $\mathrm{pH}$ & $\begin{array}{c}\mathrm{OH}^{-} \\
\text {molar }\end{array}$ & $\begin{array}{r}1 / \mathrm{OH}^{-} \\
1 / \mathrm{molar}\end{array}$ & $\begin{array}{r}\text { Pre-irrad } \\
\text { (Mrad) }\end{array}$ & $\begin{array}{r}\text { Dose Rate } \\
(\mathrm{rad} / \mathrm{hr})\end{array}$ & $\begin{array}{r}\text { Response: } \mathrm{K}+ \\
(\mathrm{mg} / \mathrm{L} / \text { day })\end{array}$ \\
\hline original design & 1 & 5.5 & 14.5 & 3.00000 & 0.333333 & 0 & 0 & 3.8 \\
\hline original design & 2 & 5.5 & 14.5 & 3.00000 & 0.333333 & 30 & 28000 & 2.9 \\
\hline original design & 3 & 5.5 & 10.4 & 0.00025 & 4000 & 0 & 28000 & 26 \\
\hline original design & 4 & 5.5 & 10.8 & 0.00060 & 1666.667 & 30 & 0 & $11(124)$ \\
\hline original design & 5 & 2.8 & 12.2 & 0.01600 & 62.5 & 15 & 15000 & 5.9 \\
\hline \multirow[t]{3}{*}{ original design } & 6 & 2.8 & 12.2 & 0.01600 & 62.5 & 15 & 15000 & 6.3 \\
\hline & 7 & 2.8 & 12.0 & 0.01000 & 100 & 15 & 15000 & 8.5 \\
\hline & 8 & 2.8 & 11.5 & 0.00300 & 333.3333 & 200 & 15000 & 1.1 \\
\hline original design & 9 & 0.65 & 13.7 & 0.50000 & 2 & 0 & 28000 & 5 \\
\hline original design & 10 & 0.65 & 13.7 & 0.50000 & 2 & 30 & 0 & 1.2 \\
\hline \multirow[t]{2}{*}{ original design } & 11 & 0.1 & 10.3 & 0.00020 & 5000 & 0 & 0 & 26 \\
\hline & 12 & 0.1 & 10.4 & 0.00025 & 4000 & 0 . & 0 & 17 \\
\hline \multirow[t]{2}{*}{ original design } & 13 & 0.1 & 10.1 & 0.00013 & 7692.308 & 30 & 28000 & 2.2 \\
\hline & 14 & 0.1 & 9.9 & 0.00010 & 10000 & 30 & 28000 & 2 \\
\hline Repeat of \#3 $\left(\mathrm{HNO}_{3}\right)$ & 15 & 5.5 & 10.3 & 0.00008 & 12500 & 0 & 28000 & 23 \\
\hline Repeat of \#3 $\left(\mathrm{CO}_{2}\right)$ & 16 & 5.5 & 10.2 & 0.00020 & 5000 & 0 & 28000 & 20 \\
\hline Repeat of \#4 $\left(\mathrm{HNO}_{3}\right)$ & 17 & 5.5 & 10.4 & 0.00016 & 6250 & 30 & 0 & $23(178)$ \\
\hline Repeat of $\# 4\left(\mathrm{CO}_{2}\right)$ & 18 & 5.5 & 10.4 & 0.00025 & 4000 & 30 & 0 & $22(159)$ \\
\hline Repeat of \#11 $\left(\mathrm{HNO}_{3}\right)$ & 19 & 0.1 & 10.1 & 0.00025 & 4000 & 0 & 0 & 38 \\
\hline Repeat of $\# 11\left(\mathrm{CO}_{2}\right)$ & 20 & 0.1 & 10.2 & 0.00013 & 7692.308 & 0 & 0 & 32 \\
\hline Repeat of $\# 13\left(\mathrm{HNO}_{3}\right)$ & 21 & 0.1 & 9.8 & 0.00016 & 6250 & 30 & 28000 & 2.4 \\
\hline \multirow[t]{5}{*}{ Repeat of $\# 13\left(\mathrm{CO}_{2}\right)$} & 22 & 0.1 & 9.8 & 0.00006 & 16666.67 & 30 & 28000 & 2.4 \\
\hline & 23 & 2.8 & 10.2 & 0.00006 & 16666.67 & 15 & 15000 & 15 \\
\hline & 24 & 2.8 & 9.9 & 0.00016 & 6250 & 15 & 15000 & 14 \\
\hline & 25 & 2.8 & 10.5 & 0.00008 & 12500 & 15 & 0 & 19 \\
\hline & 26 & 2.8 & 10.2 & 0.00016 & 6250 & 15 & 29000 & 22 \\
\hline
\end{tabular}

The ten original design points are indicated in this table. Four flasks $(7,8,12$, and 14) were added to the experimental plan to investigate the following specific conditions: for flask \# 7, $\mathrm{UO}_{2}$ was added; flask \# 8 was subjected to a very high pre-irradiation dose; for flask \# 12, the solution was under nitrogen instead of oxygen, and the solids concentration for flash \# 14 was low $(2.5 \mathrm{wt} \%)$. Some of these original design points (as indicated in Table 1) were subsequently repeated, twice, once using $\mathrm{HNO}_{3}$ and then using $\mathrm{CO}_{2}$, to help attain the target $\mathrm{pH}$.

The experimental plan was designed to generate data for the estimation of linear effects for the four factors. Flasks 5 and 6 are center points of the design region and were added to provide an opportunity for assessing the adequacy of such a linear model.

The solids stability was measured by the milligrams of $\mathrm{K}^{+}$precipitated per liter of solution per day. Note that for three of the experiments (flasks 4 and its repeats, flasks 17 and 18) two different response rates are provided in Table 1. For these experiments, there appeared to be two rates of potassium precipitation. An initial slow rate followed by an accelerated rate (shown in parentheses in Table 1) later. Many of the analyses that follow are conducted twice, first with the initial rates representing these experiments and then using the accelerated rates. 


\section{Statistical Models}

A number of statistical models were explored to investigate the relationship between these precipitated $\mathrm{K}+$ values and the factors of Table 1 . As noted above, in the analyses that follow, the data from Table 1 will used to explore the various statistical models in two ways:

(a) flasks 4,17 , and 18 represented by their initial rates (init) and

(b) these flasks represented by their accelerated rates (accel).

Also, the factors $\mathrm{Na}+$, Pre-irradiation, and dose rate were consistently included in the models that follow. The $\mathrm{pH}$ factor was introduced into these models in one of several forms, either as $\mathrm{pH}, \mathrm{OH}^{-}$, or $1 / \mathrm{OH}^{-}$. These models were analyzed using JMP®, a statistical software package from SAS Institute in Cary, NC, and they are summarized in Table 2.

\section{Table B-2: Results From Fitting The Statistical Models}

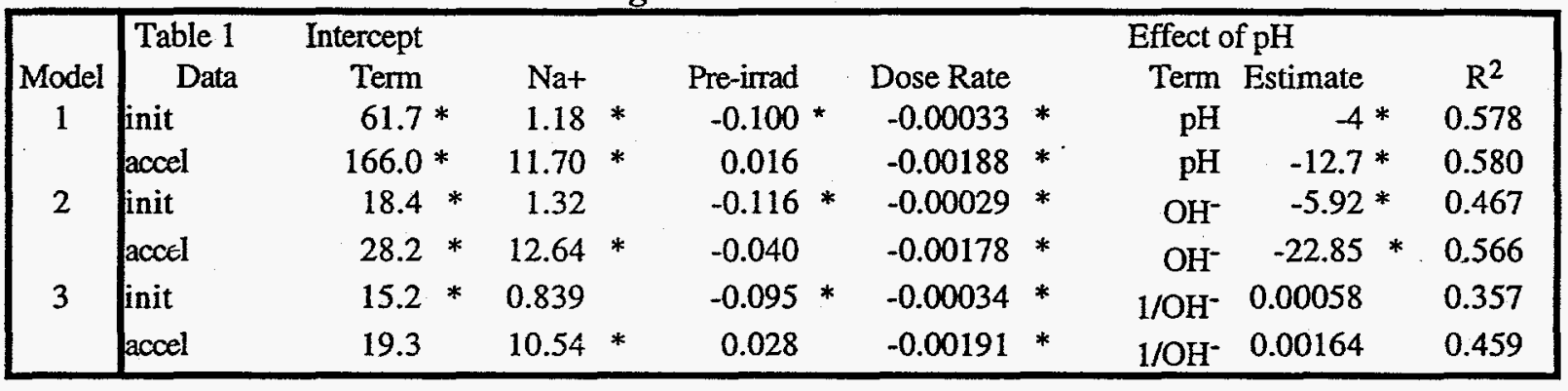

An * after a value indicates that the estimate was statistically significant at the $10 \%$; init and accel represent the use of the data in Table 1 as indicated above.

The $\mathrm{R}^{2}$ value for each of the fitted models is given. This value for a fitted model represents the fraction of the variability of the response data explained by the model. The $R^{2}$ values for these models indicate that they explain only about 36 to $58 \%$ of the variation in the $\mathrm{K}^{+}$rates. The best model (in terms of these $\mathrm{R}^{2}$ values) appears to be Model 1 which may be expressed as

(for the "init" data)

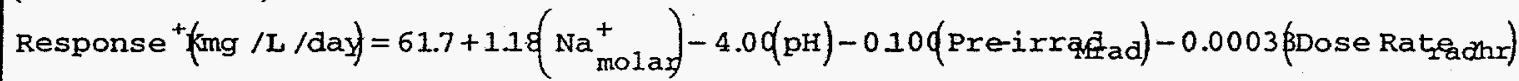

and

(for the "accel" data)

Response $^{+}(\mathrm{mg} / \mathrm{L} / \mathrm{day})=166.0+11 / 7\left(\mathrm{Na}_{\mathrm{molar}}^{+}\right)-12.7(\mathrm{pH})+0.01($ Pre-irratad $)-0.0018$ (Dose Ratreadnr $)$

\section{Other Functional Forms for the Factors}

Several other functional forms for the factors (a quadratic term for $1 / \mathrm{OH}^{-}$, sodium represented by $\exp \left(\sqrt{\mathrm{Na}_{\text {molar }}^{+}}\right)$, were explored for the data ("init" and "accel") of Table 1. The explanatory capabilities of these models, as indicated by their $\mathrm{R}^{2}$ values, are comparable to the models summarized in Table 2 . The results of fitting these special functions are provided in Table 3. 
Table B-3: Results From Fitting Additional Statistical Models

\begin{tabular}{|c|c|c|c|c|c|c|c|c|}
\hline \multirow{3}{*}{$\begin{array}{c}\text { Model } \\
4\end{array}$} & Table 1 & Intercept & & & & Effect o & $f \mathrm{pH}$ & \\
\hline & Data & Term & $\mathrm{f}(\mathrm{Na})$ & Pre-irrad & Dose Rate & Term & Estimate & $\mathbf{R}^{2}$ \\
\hline & init & $60.9 *$ & $0.704 *$ & $-0.099 *$ & $-0.00033 *$ & $\mathrm{pH}$ & & 0.579 \\
\hline \multirow{3}{*}{5} & accel & $158.4 *$ & $7.198 *$ & $0.030 *$ & $-0.00188 *$ & $\mathrm{pH}$ & -12.8 & 0.600 \\
\hline & init & $17.4 *$ & $0.817 *$ & $-0.115 *$ & $-0.00029 *$ & $\mathrm{OH}^{-}$ & -6.02 & 0.472 \\
\hline & accel & 18.4 & $7.911 *$ & -0.026 & $-0.00178 *$ & $\mathrm{OH}^{-}$ & -23.96 & 0.595 \\
\hline \multirow[t]{2}{*}{6} & init & $14.6 *$ & 0.507 & $-0.094 *$ & $-0.00034 *$ & $1 / \mathrm{OH}^{-}$ & $\cdot 0.00058$ & 0.358 \\
\hline & accel & 11.1 & $6.518 *$ & 0.042 & $-0.00191 *$ & $11 \mathrm{OH}^{-}$ & 0.00168 & 0.477 \\
\hline \multirow[t]{4}{*}{7} & init & $8.9 *$ & 0.562 & -0.071 & $-0.00032 *$ & $1 / \mathrm{OH}^{-}$ & 0.00321 & * \\
\hline & & & & & & $\left(1 / \mathrm{OH}^{-}\right)^{2}$ & $-1.767 e-7$ & 0.554 \\
\hline & accel & -6.4 & $6.684 *$ & 0.112 & $-0.00184 *$ & $1 / \mathrm{OH}^{-}$ & 0.00964 & * \\
\hline & & & & & & $\left(1 / \mathrm{OH}^{-}\right)^{2}$ & $-5.352 e-7$ & 0.557 \\
\hline \multirow{6}{*}{$\begin{array}{c}\text { Model } \\
8\end{array}$} & Table 1 & Intercept & & & & Effect 0 & $f \mathrm{pH}$ & \\
\hline & Data & Term & $\mathrm{Na}+$ & Pre-irrad & Dose Rate & Term & Estimate & $\mathrm{R}^{2}$ \\
\hline & init & $9.4 *$ & 0.973 & -0.072 & -0.00032 & $1 / \mathrm{OH}^{-}$ & 0.00324 & \\
\hline & & & & & & $\left(1 / \mathrm{OH}^{-}\right)^{2}$ & $-1.783 e-7$ & 0.557 \\
\hline & accel & 1.2 & $10.953 *$ & 0.100 & $-0.00184 *$ & $1 / \mathrm{OH}^{-}$ & 0.00984 & .. \\
\hline & & & & & & $\left(1 / \mathrm{OH}^{-}\right)^{2}$ & $-5.508 e-7$ & * 0.556 \\
\hline
\end{tabular}

An* after a value indicates that the estimate was statistically significant at the $10 \%$; init and accel represent the use of the data in Table 1 as indicated above; and $\mathrm{f}(\mathrm{Na})$ is used to represent $\left.\exp \sqrt{\mathrm{Na}_{\text {molar }}^{+}}\right)$.

A Comparison of $\mathrm{pH}$ Adjustments Using $\mathrm{HNO}_{3}$ Versus $\mathrm{CO}_{2}$

The set of repeated experiments (flasks 15-22) used different mechanisms to adjust the $\mathrm{pH}$ (as indicated in Table 1): nitric acid $\left(\mathrm{HNO}_{3}\right)$ and carbon dioxide $\left(\mathrm{CO}_{2}\right)$. This provides an opportunity to test for an effect in the response due to this difference. The appropriate test (for the init and accel data) is in the form of a paired-t test which is provided in the following figures.

\section{Figure B-1. Paired Comparison of K+ Rates (Initial and Accelerated)}
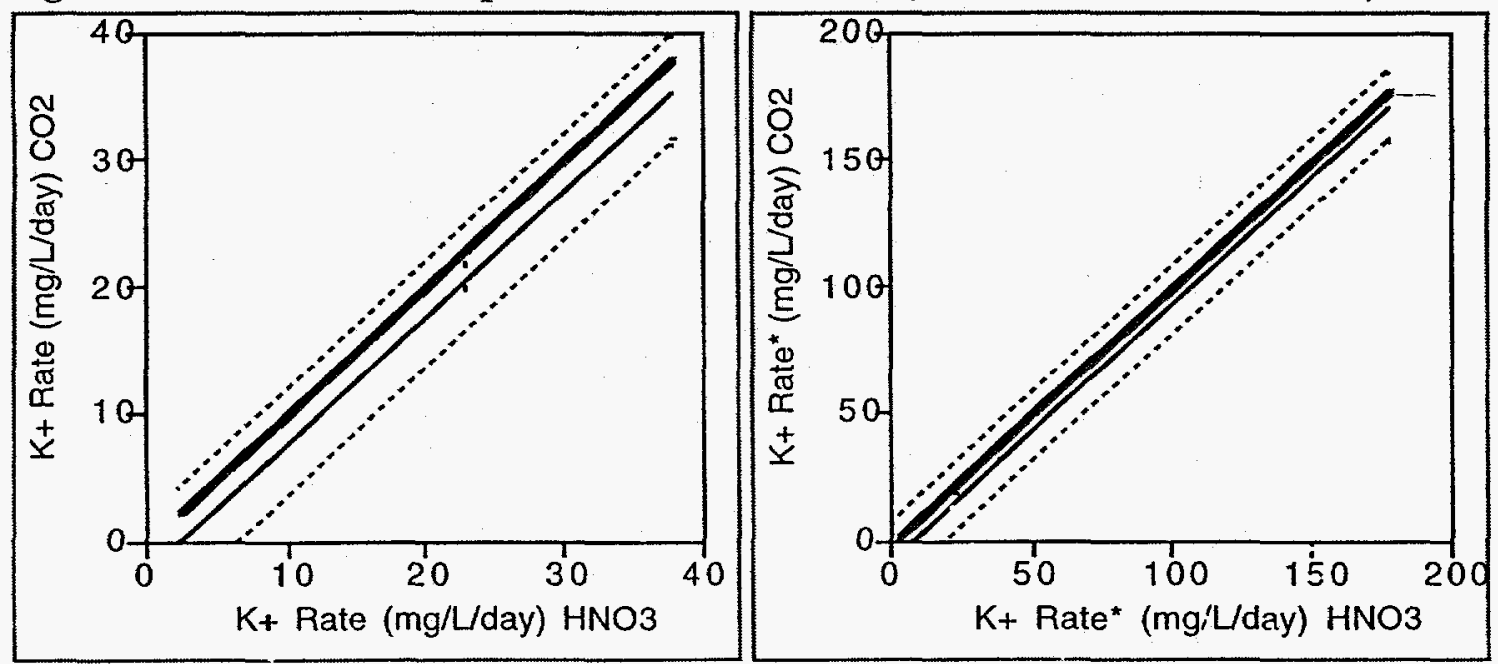

These are plots of the decomposition rates for the carbon dioxide experimental runs versus the nitric acid. The solid bold line on the diagonal shows where the points would fall if there was no effect on the response 
due to the different $\mathrm{pH}$ adjustment mechanisms. The second solid line indicates the estimated effect from these data with the dotted lines being $95 \%$ confidence limits for this estimated effect. The responses for the nitric acid adjustments are somewhat higher than their corresponding carbon dioxide experiments. However, since the bold line is within the confidence limits, there is no indication of a statistical difference between the $\mathrm{HNO}_{3}$ and $\mathrm{CO}_{2}$ adjustments at the $5 \%$ significance level. The statistical details of these results are given in the following exhibits (a Prob > It value less than 0.05 would indicate a significant difference):

\begin{tabular}{|c|c|c|c|}
\hline \multicolumn{4}{|c|}{$\begin{array}{l}\text { Paired } t \text {-Test for "init" Data } \\
\text { K+Rate (mg/L/day) } \mathrm{HNO} 3 \text { - K+ Rate (mg/L/day) } \mathrm{CO} 2\end{array}$} \\
\hline $\begin{array}{l}\text { Mean Difference } \\
\text { Std Error } \\
\text { t-Ratio } \\
\text { DF }\end{array}$ & $\begin{array}{r}2.5 \\
1.322876 \\
1.889822 \\
3\end{array}$ & $\begin{array}{l}\text { Prob }>|t| \\
\text { Prob }>t \\
\text { Prob }<t\end{array}$ & $\begin{array}{l}0.1552 \\
0.0776 \\
0.9224\end{array}$ \\
\hline
\end{tabular}

\begin{tabular}{|c|c|c|c|}
\hline \multicolumn{4}{|c|}{$\begin{array}{l}\text { Paired t-Test for "accel" Data } \\
\qquad \mathrm{K}+\mathrm{Rate}^{*}(\mathrm{mg} / \mathrm{L} / \text { day }) \mathrm{HNO} 3-\mathrm{K}+\text { Rate* (mg/L/day) } \mathrm{CO} 2\end{array}$} \\
\hline $\begin{array}{l}\text { Mean Difference } \\
\text { Std Error } \\
\text { t-Ratio } \\
\text { DF }\end{array}$ & $\begin{array}{r}7 \\
4.1833 \\
1.67332 \\
3\end{array}$ & $\begin{array}{l}\text { Prob }>|t| \\
\text { Prob }>t \\
\text { Prob }<t\end{array}$ & $\begin{array}{l}0.1929 \\
0.0964 \\
0.9036\end{array}$ \\
\hline
\end{tabular}

Additional data from other paired $\mathrm{HNO}_{3}$ and $\mathrm{CO}_{2}$ experiments would allow for a more sensitive statistical test for a difference in the responses.

\section{Concluding Comments}

Based upon the results presented in Tables 2 and 3, several models indicate that the factors studied in these experiments have statistically significant effects on KTPB decomposition. The low $\mathrm{R}^{2}$ values, however, indicate that the models explain only a small portion of the variability seen in these responses. Introducing additional factors in future experimentation and, possibly, exploring more complicated statistical models may be helpful in improving the understanding of the significant effects. 
Keywords: In-Tank Process, Benzene

Retention: Permanent

CC: G. A. Aberra, 704-S

K. Andringa, 773-41A

J. L. Barnes, 704-S

M. J. Barnes, 773-A

T. E. Britt, 703-H

B. T. Butcher, 773-43A

J. T. Carter, 704-25S

G. L. Cauthen, 241-119H

W. C. Clark, 704-56H

C. L. Crawford, 773-41A

N. R. Davis, 703-H

D. E. Doughty, 704-56H

L. O. Dworjanyn, 779-2A

T. B. Edwards, 773-41H

H. H. Elder, 704-S

T. J. Fiske, 241-120H

J. R. Fowler, 703-H

F. R. Graham, 773-A

M. S. Hay, 773-A

D. T. Hobbs, 773-A

E. W. Holtzscheiter, 773-A

R. A. Jacobs, 704-T

M. D. Johnson, 703-H

M. T. Keefer, $704-56 \mathrm{H}$

P. S. Kirkland, 703-46A

L. F. Landon, 704-T

T. J. Lex, 703-H

L. S. Livingston, $703-\mathrm{H}$

P. E. Lowe, 773-41A

D. J. McCabe, 773-43A

J. W. McCullough, 703-H

J. D. Menna, 730-2B

M. S. Miller, $704-56 \mathrm{H}$

J. P. Morin, 703-H

C. A. Nash, 676-1T

L. M. Nelson, 773-43A

L. M. Papouchado, 773-A

S. F. Piccolo, 704-56H

R. A. Peterson, 773-41A
C. T. Randal1, 704-T

P. L. Rutland, 242-152H

R. M. Satterfield, 703-H

W. E. Stevens, 773-A

P. C. Suggs, 703-H

R. F. Swingle, 773-A

W. L. Tamosaitis, 773-A

M. C. Thompson, 773-A

C. Tuckfield, 773-41A

W. B. Vanpelt, 773-42A

D. D. Walker, 773-A

W. R. Wilmarth, 773-42A

G. T. Wright, 773-A

TIM, 703-43A

LWP Files c/O A. Patterson, 773-A

ITP Files c/o A.G. Wiest, $241-119 \mathrm{H}$ 